\title{
Synonymous Mutations of Porcine Igf1r Extracellular Domain Affect Differentiation and Mineralization in MC3T3-E1 Cells
}

Chunli Wang ${ }^{\dagger}$, Siyao Wang ${ }^{\dagger}$, Songcai Liu, Yunyun Cheng, Hongwei Geng, Rui Yang,
Tianqi Feng, Guanhong Lu, Xiaotong Sun, Jie Song and Linlin Hao*

College of Animal Sciences, Jilin University, Changchun, China

Owing to the wide application of miniature pigs in biomedicine, the formation mechanism of its short stature must be elucidated. The insulin-like growth factor 1 receptor (IGF$1 \mathrm{R})$, which receives signals through the extracellular domain (ECD) binding with ligands, is crucial in regulating cell growth and bone matrix mineralization. In this study, two haplotypes of Igf1r with four synonymous mutations in the coding sequences of IGF1R ECD between large pigs (LP) and Bama pigs (BM) were stably expressed in the Igf1r-knockout MC3T3-E1 cells and named as MC3T3-LP cells (LP group) and MC3T3BM cells (BM group), respectively. IGF-1R expression was lower in the BM group than in the LP group both in terms of transcription and translation levels, and IGF$1 \mathrm{R}$ expression inhibited cell proliferation. In addition, IGF-1R expression in the BM group promoted early-stage differentiation but delayed late-stage differentiation, which not only suppressed the expression of bone-related factors but also reduced alkaline phosphatase activity and calcium deposition. Moreover, different haplotypes of lgfir changed the stability and conformation of the protein, further affecting the binding with IGF-1. Our data indicated that the four synonymous mutations of IGF1R ECD encoded by affect gene transcription and translation, thereby further leading to differences in the downstream pathways and functional changes of osteoblasts.

Keywords: synonymous mutations, IGF-1R, cell differentiation, osteoblast mineralization, protein conformation

\section{INTRODUCTION}

Miniature pigs possess many similarities with humans in terms of anatomical, morphological, and physiological characteristics. Hence, miniature pigs have invaluable advantages as biomedical animal models (Liu et al., 2010). With the development and utilization of miniature pig models, current studies focus on xenotransplantation and model construction. However, a systematic study on the formation mechanism of miniature pig dwarfism is lacking (Cheng et al., 2018; Cao et al., 2019). The genetic background of miniature pigs and the mechanism of dwarfism are the prerequisites of scientific research using miniature pig models. Therefore, the formation mechanism of miniature pigs must be elucidated. In China, the Bama Xiang pig is a well-known miniature pig breed from Guangxi Zhuang Autonomous Region. It is characterized by highly 
inbred, stable heredity and mini-body size (the mean body weight of adults is nearly $40 \mathrm{~kg}$ ) (Cheng et al., 2016; Yang et al., 2018). The Large White pig also called Yorkshire pigs, is considered the most representative of large pigs because of its large body size and high growth rate (mean body weight of adults is almost $250 \mathrm{~kg}$ ) and is considered as the most typical representative of large pigs. The contrast in the size and bodyweight of these two breeds makes them an ideal model for comparing the differences in body size between miniature and large pigs. Moreover, bone size (bone mass, volume) and bone growth are regarded as important indicator of body size in mammals (Ruff, 2003; Nieves et al., 2005; Schlecht et al., 2015). Cellular signaling pathways controlled by growth factors and hormones are also believed to influence bone size and bone growth (Efstratiadis, 1998).

The insulin-like growth factor-1 receptor (IGF-1R) is a typical receptor tyrosine kinase that regulates embryonic and postnatal growth (Efstratiadis, 1998; Siddle, 2011). An intragenic IGF-1R deletion that was identified in a patient presented short stature (Harmel et al., 2013). IGF-1R signaling, which is activated by IGF-1, plays an essential role in cell growth and development, as well as in bone formation via osteoblastmediated bone mineralization (Fang et al., 2019). IGF-1R is also involved in bone matrix mineralization. Studies using osteoblast culture systems have shown that IGF-1R, by binding to IGF-1, enhances bone matrix production and stimulates the proliferation and differentiation of osteoblasts (Canalis, 1993; Birnbaum et al., 1995; Wang et al., 2015). IGF-1R signaling activates autophagy, which is necessary for stimulating early osteoblast differentiation, at the early stage of differentiation by activating AMPK (Xi et al., 2016).

IGF-1R exhibits different protein expression levels in the liver and muscle tissues of large and miniature pigs (Cheng et al., 2016). A previous study screened nine strong linkage synonymous mutations in the coding sequence (CDS) of IGF$1 \mathrm{R}$ between large and miniature pigs, four of which were found in the extracellular domain (ECD), whereas five were located in the intracellular domain (ICD) (Changhong et al., 2018). As a ligand-dependent receptor, mutations in IGF-1R ECD can potentially affect its biological function. A clinical research indicated that mutations in Egfr are associated with Igflr variants in female patients with lung adenocarcinoma (Liu et al., 2016). A study showed that the mutant of V599E-IGF-1R ECD interferes with the receptor's transport processes, thereby eliminating the processing of pro-receptors and localization of the plasma membrane (Wallborn et al., 2010). However, most studies presently focus on the missense mutations of $\mathrm{Ig} f 1 \mathrm{r}$ (Wallborn et al., 2010; Liu et al., 2016). A systematic functional research on synonymous mutations is lacking.

Changes in synonymous codons that do not alter the final protein sequence were previously regarded as silent mutations without any functional consequences. Most recent evidence shows that synonymous mutations are shaped by evolutionary selection and affects other aspects of protein biogenesis (Chaney and Clark, 2015). Advances in synthetic biology have provided researchers with new methods for understanding the diverse roles of synonymous variations (Hunt et al., 2014). Synonymous codon usage affects multiple steps of transcription and translation processes, including regulation of speed and accuracy of the translation, co-translational folding, protein post-translational modifications, secretion, and expression levels (Plotkin and Kudla, 2011). Therefore, exploring the functions of synonymous mutations may be the key to uncovering the influence mechanism of the correlation between gene polymorphisms and phenotypes.

Although the growth-related traits of Angus cattle have been proved to be related to a synonymous mutation of Igfir (Szewczuk et al., 2013), the question of whether the synonymous mutations in Igflr can affect the body size traits in pigs remains unclear. Moreover, the potential functions of these synonymous mutations have yet to be recognized. In the present study, we focused on four single nucleotide polymorphisms (SNPs) of IGF-1R ECD previously screened from pigs of different body size traits (Figure 1A and Table 1) to confirm the effects of synonymous mutations on the differentiation and mineralization of osteoblasts. We further clarified the molecular mechanism of bone development to determine the effects of Igf1r synonymous mutations on the formation of body shape traits. We expected to provide new evidence clarifying the roles of IGF-1R in the formation mechanism of miniature pigs.

The linkage effects of these synonymous mutations may be involved in the formation of body size in miniature pigs. The present study explored the functions of potentially valuable synonymous mutations and provided a theoretical basis for the formation of body size in miniature pigs. According to the results, we indeed observed differences of IGF-1R at both mRNA and protein levels between the two haplotypes of IGF-1R from large and miniature pigs. Furthermore, these cellular and biochemical alterations affected the stability of IGF-1R and its ability to bind its ligand. Importantly, our results reveal that four synonymous mutations of IGF-1R contribute to the consequent changes in IGF-1R signaling and cellular functions observed in the proliferation, differentiation, and mineralization of osteoblasts.

\section{MATERIALS AND METHODS}

\section{Construction of sgRNA and PiggyBac Vectors}

The sgRNA vector was constructed as follows: One sgRNA of Igf1 $r$ in exon 4 was designed by the Crispr/cas9 sgRNA prediction website $^{1}$, and the PX458 knockout vectors containing the sgRNA were constructed (Zafra et al., 2018). The sgRNA forward primer was 5'-CACCGCAATCTGCTTATTAACATC-3', whereas the reverse primer was $5^{\prime}$-AAACGATGTTAATAAGCAGATTGC-3'. The PiggyBac vector was constructed as follows: Two fusion genes were made using the CDS of Igflr ICD to splice the ECD of the Large White pig and Bama Xiang pig. Two fusion genes contained the FLAG tag sequence and enzyme recognition sequences, which were then synthesized by Jilin Comate Bioscience Co., Ltd (China), and the FLAG tag sequence was added to C-terminal tail of IGF-1R (Figures $\mathbf{1 A}, \mathbf{B}$ and Table 1). The fusion genes were successfully connected to the pB513B-Puro vector (MiaoLingBio, China). These genes were

\footnotetext{
${ }^{1}$ https://zlab.bio/guide-design-resources
} 


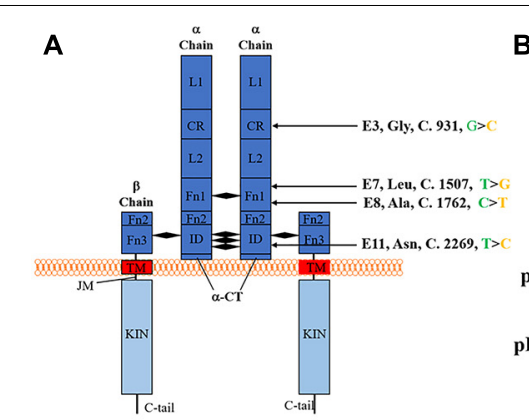

D

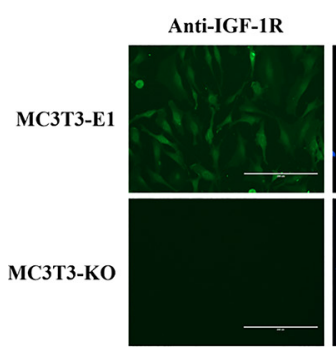

B

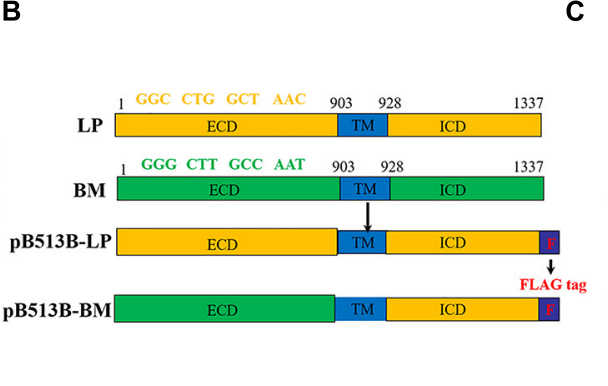

E

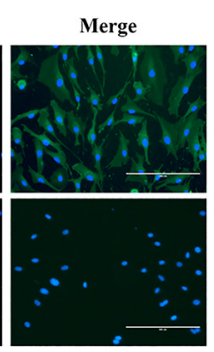

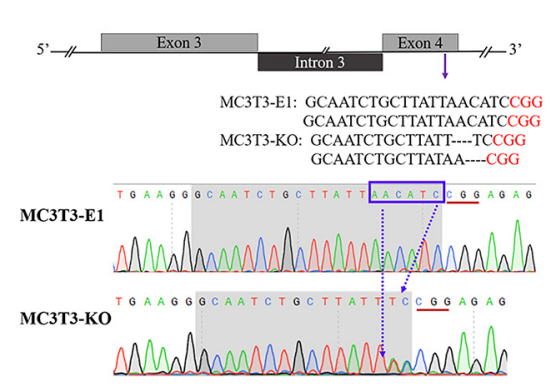

$\mathbf{F}$

FIGURE 1 | Generating Igf1r-Knockout MC3T3-E1 Clones. (A) Four SNPs were located in the coding sequence of the Igf1r gene ECD between miniature (green) and large (yellow) pigs. (B) The full-length Igf1r of large pigs (LP) and Bama Xiang pigs (BM) were shown in the top line. The sequences were inserted into the pB513 vector between the ECoRI and Xhol sites and respectively named as pB513B-LP (with the CDS of full lgf1r of Large White pigs) and pB513B-BM (with the CDS of IGF-1R ECD of Bama Xiang pigs and IGF-1R ICD of Large White pigs). TM: transmembrane region (blue), F: FLAG tag (purple). (C) Schematic illustration and DNA sequence map showing the position of sgRNA target site. The target sequence and PAM sequence were highlighted by the gray background and red underline, respectively. (D) Immunostaining of IGF-1R (Green) and DAPI (Cyan) in MC3T3-E1 and MC3T3-KO cells. (E) The protein expression levels of IGF-1R in MC3T3-E1 and MC3T3-KO cells were analyzed by western blot. (F) Quantification of the (E) western blot results.

named pB513B -LP (with the CDS of full Igf1r of Large White pigs) and pB513B-BM (with the CDS of Igf1r ECD of Bama Xiang pigs and Igflr ICD of Large White pigs) (Figure 1B).

\section{Cell Culture}

Given that the osteoblast cell lines of pigs are difficult to obtain, a mouse osteoblast cell line (MC3T3-E1 cells), which was obtained from the Hospital of Stomatology Jilin University, was selected. The IGF-1R amino acid sequences in mice (NP_034643.2) were found to be $95 \%$ similar to those in humans (NP_000866.1) and pigs (NP_999337.1) according to $\mathrm{NCBI}^{2}$. Moreover, a certain amount of IGF-1R was detected in MC3T3-E1 cells (Joung et al., 2013). The cells were cultured in Dulbecco's minimal essential medium (DMEM) (Hyclone, United States)

${ }^{2}$ https://blast.ncbi.nlm.nih.gov/Blast.cgi

TABLE 1 | SNPs parameters of IGF-1R gene ECD in Bama Xiang pigs and large pigs.

\begin{tabular}{|c|c|c|c|c|}
\hline \multirow[t]{2}{*}{ SNP number } & \multicolumn{2}{|c|}{ Gene } & \multirow{2}{*}{$\frac{\text { mRNA }}{\text { Allele change }}$} & \multirow{2}{*}{$\frac{\text { Protein }}{\text { Position }}$} \\
\hline & Position & Exon & & \\
\hline rs338724264 & g.267380 & 3 & $\mathrm{G} / \mathrm{C}$ & 301 \\
\hline rs325909655 & g.286723 & 7 & $\mathrm{~T} / \mathrm{G}$ & 493 \\
\hline rs337838116 & g.288540 & 8 & $\mathrm{C} / \mathrm{T}$ & 578 \\
\hline rs326728191 & g.296721 & 11 & $\mathrm{~T} / \mathrm{C}$ & 747 \\
\hline
\end{tabular}

supplemented with $10 \%$ heat-inactivated fetal bovine serum and $1 \%$ streptomycin/penicillin (Gibco, United States) in an incubator with $5 \% \mathrm{CO}_{2}$ at $37^{\circ} \mathrm{C}$. At $80 \%$ cell confluence, the culture medium was changed to a differentiation medium that contained $50 \mathrm{mg} / \mathrm{mL}$ ascorbic acid (Sigma, United States) and $10 \mathrm{mmol} / \mathrm{L} \beta$-glycerophosphate (Sigma, United States) (Zheng et al., 2018).

\section{Igf1r Knockout in MC3T3-E1 Cell Lines}

Exactly $30 \mu \mathrm{g}$ of PX458-sgRNA vectors were transfected into MC3T3-E1 cells by using the BTX-ECM 2001 Electroporation system (United States). Two days after electroporation, the cells expressing the GFP fluorescent protein were separated via flow cytometry for further culture. A few days later, the monoclonal cells were selected and seeded in 24-well plates. When the cells became confluent, NP40 lysis buffer was used to lyse a few cells. The lysate was used as the PCR template for genotyping to identify the knockout activity, and IGF-1R antibody was used for Western blot and immunofluorescence assays further to verify the expression of IGF-1R in MC3T3-E1 cells.

\section{Generation of Two Recombinant Cell Lines}

Exactly $30 \mu \mathrm{g}$ of pB513B-LP and pB513B-BM vectors and $12 \mu \mathrm{g}$ PiggyBac transposase vector were successively co-transfected into MC3T3-KO cells using the BTX-ECM 2001 electroporation 
system. Two days after electroporation, the cells transfected with pB513B-puro vectors were screened with puromycin $(3 \mu \mathrm{g} / \mathrm{ml})$. After 9 days, individual cell clones were selected and seeded in 24-well plates. When the cells became confluent, NP40 lysis buffer was used to lyse a few cells. Genotyping was performed using lysate as the PCR template. The integrated Igfir gene copy number per genome was determined via quantitative realtime PCR (q-PCR). q-PCR was performed using SYBR Select Master Mix (Roche). The primers used are listed in Table 2. For each sample, $100 \mathrm{ng}$ of the DNA template was amplified in PCR reactions on an ABI PRISM 7900HT thermocycler (Applied Biosystems, United States). All samples were performed in triplicate, and each quantification data represented an average of at least three measurements. A standard curve for the Igflr gene copy number was generated according to the continuous dilution of $\mathrm{pB} 513 \mathrm{~B}$ genetic recombination vector. The transgene Igf1r copy number per diploid cell was then calculated as described previously (Joshi et al., 2008; Wang et al., 2013). Finally, the expression of IGF-1R in MC3T3-KO was verified by FLAG antibody. The positive clones were named as MC3T3LP and MC3T3-BM.

\section{Immunofluorescence Assay}

Paraformaldehyde (4\%) was used to fix cells for $20 \mathrm{~min}$, and $0.5 \%$ Triton X-100 in PBS was utilized to permeabilize the cells for $10 \mathrm{~min}$. Subsequently, $10 \%$ fetal bovine serum was used to block the cells for $1 \mathrm{~h}$. Finally, the cells were incubated with IGF-1R antibody (Abcam, United States) at $4^{\circ} \mathrm{C}$ overnight. On the following day, FITC-labeled immunofluorescence secondary antibody (Bioworld, United States) was added to plates of cells for incubation for $1 \mathrm{~h}$ in the dark. Then, 4-6-diamino-2-phenindole (Bioworld, United States) was used to visualize the nucleus. Images were captured using a fluorescence microscope (Leica, Frankfurt, Germany).

\section{RNA Extraction and qRT-PCR}

The RNAiso Plus reagent (Takara, United States) was used to extract total RNA from the cells according to the manufacturer's instructions. Reverse transcription was performed to generate cDNA using a reverse transcription kit. SYBR Select Master Mix (Roche) was used for Quantitative Real-time PCR (qRT-PCR). The primers used are listed in Table 3. The PCR reactions were performed on an ABI PRISM 7900HT thermocycler (Applied Biosystems, United States), and $10 \mathrm{ng}$ of the cDNA template was amplified for each sample. All samples were repeated three times, and each mRNA quantification data represented the average of these three measurements. The $\mathrm{Ct}$ values of the target genes

TABLE 2 | Primer information for qPCR analysis of copy number.

\begin{tabular}{|c|c|c|c|}
\hline Gene & Sequences $\left(5^{\prime}-3^{\prime}\right)$ & $\begin{array}{l}\text { Product } \\
\text { lengths (bp) }\end{array}$ & $\operatorname{Tm}\left({ }^{\circ} \mathrm{C}\right)$ \\
\hline PB & $\begin{array}{l}\text { F: TCACGCGGTCGTTATAGTTCAA } \\
\text { R: CCGTGAGGCGTGCTTGTC }\end{array}$ & 62 & 58.5 \\
\hline$\beta$-actin & $\begin{array}{l}\text { F: TTCAACACCCCAGCCATGTA } \\
\text { R: TGTGGTACGACCAGAGGCATAC }\end{array}$ & 69 & 58.5 \\
\hline
\end{tabular}

were normalized by the $\mathrm{Ct}$ value of the $\beta$-actin gene. The $2^{-\Delta \mathrm{Ct}}$ method was employed to quantify and normalize the expression data (Cheng et al., 2020).

\section{Immunoblotting Assay}

Protein content was quantified using a BCA protein assay kit (Beyotime, China) following the manufacturer's protocols. About $40 \mu \mathrm{g}$ of the total proteins of each sample were separated using 12 or $8 \%$ SDS-PAGE gels. The total proteins were transferred to polyvinylidene difluoride membranes. Afterward, 10\% nonfat dry milk dissolved in TBST buffer was used to block the membranes for $1.5 \mathrm{~h}$ at $37^{\circ} \mathrm{C}$. Thereafter, the primary antibodies were used to incubate with the membranes overnight at $4^{\circ} \mathrm{C}$, followed by incubation with horseradish peroxidase-labeled antimouse IgG or anti-rabbit IgG (Bioworld, United States) for $1.5 \mathrm{~h}$ at room temperature. Finally, the proteins were detected using the enhanced chemiluminescence plus Western blot detection system (Amersham Biosciences). The primary antibodies used in this study were as follows: phospho-AKT (S473), AKT, and phosphoULK-1 (S555) (Cell Signaling, Beverly, MA, United States); phosphor-mTOR (S2448), phospho-AMPK (T172 and S485), AMPK, FLAG, and IGF-1R (Abcam, United Kingdom); Beclin1, ULK1, mTOR, OPN, and collagen I (WanLeiBio, China); and $\beta$-actin (BBI, China). Protein quantifications were analyzed using the GenoSens gel analysis software.

\section{Cell Proliferation}

Cell proliferation assays were performed using Cell Counting Kit-8 (CCK-8, Dojindo, Japan). MC3T3-KO, MC3T3-LP, and MC3T3-BM cells were inoculated in 96-well plates at an initial density of $6.0 \times 10^{3}$ cells/well in $100 \mu \mathrm{L}$ of culture medium.

At $0,24,48$, and $72 \mathrm{~h}, 10 \mu \mathrm{L}$ of the CCK- 8 reagent was added to each well and reacted at $37^{\circ} \mathrm{C}$ for $1 \mathrm{~h}$. Absorbance was detected using a microplate reader (TECAN, Switzerland) at a wavelength of $450 \mathrm{~nm}$.

TABLE 3 | Primer information for RT-qPCR analysis of expression of target genes.

\begin{tabular}{|c|c|c|c|}
\hline Gene & Sequences $\left(5^{\prime}-3^{\prime}\right)$ & $\begin{array}{c}\text { Product } \\
\text { lengths (bp) }\end{array}$ & $\operatorname{Tm}\left({ }^{\circ} \mathrm{C}\right)$ \\
\hline \multirow[t]{2}{*}{ Col-1 } & F: CCAGCCGCAAAGAGTCTACA & 170 & 58.5 \\
\hline & R: TTCCACGTCTCACCATTGGG & & \\
\hline \multirow[t]{2}{*}{ Opn } & F: ACACTTTCACTCCAATCGTCC & 240 & 58.5 \\
\hline & R: TGCCCTITCCGTTGTTGTCC & & \\
\hline \multirow[t]{2}{*}{ Ocn } & F: AGACTCCGGCGCTACCTT & 203 & 58.5 \\
\hline & R: CTCGTCACAAGCAGGGTTAG & & \\
\hline \multirow[t]{2}{*}{ Runx2 } & F: GAGGGACTATGGCGTCAAACA & 70 & 58.5 \\
\hline & R: GGATCCCAAAAGAAGCTITGC & & \\
\hline \multirow[t]{2}{*}{ Osterix } & F: TCAGCCGCCCCGATCTTCCA & 157 & 58.5 \\
\hline & R: CAATGGGTCCACCGCGCCAAG & & \\
\hline \multirow[t]{2}{*}{ Alp } & F: CAACAGGGTAGATTCTCTTGG & 135 & 58.5 \\
\hline & R: GGTCAGATCCAGAATGTTCC & & \\
\hline \multirow[t]{2}{*}{$\operatorname{lgf1r}$} & F: CAAGGCTGAGAACGGCCC & 160 & 58.5 \\
\hline & R: TCACTTGTCATCGTCGTCCTTG & & \\
\hline \multirow[t]{2}{*}{$\beta$-actin } & F: GGCTGTATTCCCCTCCATCG & 154 & 58.5 \\
\hline & R: CCAGTTGGTAACAATGCCATGT & & \\
\hline
\end{tabular}




\section{Measurement of Alkaline Phosphatase (ALP) Activity}

MC3T3-LP, MC3T3-BM, and MC3T3-KO cells with a density of $2.0 \times 10^{4}$ cells/well were inoculated in 24-well plates and cultured in differentiation media. The cells were eventually harvested after $3,5,7,9,14,18$, and 21 days. Alkaline phosphatase (ALP) activities were determined using an ALP kit (Nanjing Jiancheng, China) in accordance with the manufacturer's instructions. Protein concentrations were measured using a BCA protein assay kit (KeyGEN BioTECH, China). Enzyme activity was quantified via absorbance measurements at $520 \mathrm{~nm}$ using a 96-well microplate reader (TECAN, China) and calculated according to protein concentrations. Total protein content was used to normalize ALP activity, and all assays were repeated at least three times.

\section{Alizarin Red Staining (ARS)}

Mineralization is considered the last stage of osteogenic differentiation, and the formation of mineralized nodules is a definitive marker of osteoblast mineralization. Alizarin Red (AR) chelates with calcium ions are usually used to form orange-red depositions (mineralized nodules) to determine the osteogenic mineralization ability in tissues or cells (Puchtler et al., 1969; Xi et al., 2016; Zheng et al., 2018). MC3T3-LP, MC3T3-BM, and MC3T3-KO cells with a density of $2.0 \times 10^{4}$ cells/well were inoculated in 24-well plates and cultured in differentiation media for 7, 14, and 21 days. PBS was used to wash the cells twice before they were fixed with $70 \%$ ethanol for $1 \mathrm{~h}$ and stained with $1 \% \mathrm{AR}(\mathrm{pH} \mathrm{7.2)}$ ) for $10 \mathrm{~min}$ at room temperature. Afterward, the cells were washed with $\mathrm{ddH}_{2} \mathrm{O}$ twice and dried. The images were captured at $10 \times$ magnification on the inverted phasecontrast microscope (Nikon, Japan) (Bae et al., 2017). The stained nodules were dissolved with $10 \%$ cetylpyridinium chloride to quantify the degree of staining, and the absorbance at $562 \mathrm{~nm}$ (Jiang et al., 2019) was measured using a microplate reader (TECAN, China). The results were replicated in at least three independent experiments.

\section{Stability Assay}

MC3T3-LP and MC3T3-BM cells with a density of $3.0 \times 10^{5}$ cells/well were inoculated in 6-well plates. Actinomycin D (ActD, $5 \mu \mathrm{g} / \mathrm{mL}$ ) and cycloheximide (CHX, $50 \mu \mathrm{g} / \mathrm{mL}$ ) were added to the medium and used to block mRNA transcription and protein synthesis respectively. The cells were collected at $0,1,2,3$, and $4 \mathrm{~h}$ after culture, and the total RNAs and proteins were extracted. The stability of the mRNAs and proteins was detected from the collected RNAs and proteins, respectively.

\section{Co-immunoprecipitation Analysis (Co-IP)}

Exactly $500 \mathrm{nM}$ IGF- 1 was added to the medium because previous studies reported that $500 \mathrm{nM}$ IGF-1 reaches the maximum binding concentration when IGF-1R is combined with IGF-1 (Jansson et al., 1997; Whitten et al., 2009). The MC3T3-LP, MC3T3-BM and MC3T3-KO cells were incubated in the medium containing IGF-1 for $6 \mathrm{~h}$. Subsequently, the cells were collected and lysed. Co-IP incubation was performed using Pierce ${ }^{\mathrm{TM}}$ protein A/G magnetic beads (Thermo, United States). The lysate was centrifuged at $13,000 \times g$ for $15 \mathrm{~min}$, and the supernatant was immunoprecipitated overnight with IGF-1R antibody or IgG antibody (control). On the following day, the magnetic beads and the antigen-antibody complex was incubated for $2 \mathrm{~h}$ at $4^{\circ} \mathrm{C}$. The collected protein and magnetic bead complexes were washed five times with a wash buffer and eluted with an elution buffer. Finally, the eluents were neutralized with a neutralization buffer and boiled in a protein sample buffer under reducing conditions. The sample proteins were resolved and analyzed via SDS-PAGE analysis and Western blot, respectively.

\section{Flow Cytometry Analysis}

The MC3T3-LP, MC3T3-BM and MC3T3-KO cells were incubated with $4 \%$ paraformaldehyde alone or incubated with $4 \%$ paraformaldehyde and permeabilized with $0.1 \%$ Triton X100 to evaluate the cell surface expression of IGF-1R in the cells (Rezgui et al., 2009). The cells were stained with FITC-conjugated antiFLAG antibody (1:400, Abcam, United States) and analyzed via flow cytometry (BD FACSAriaII) (Ip et al., 2018).

The MC3T3-LP, MC3T3-BM and MC3T3-KO cells were incubated in $4 \%$ paraformaldehyde for $20 \mathrm{~min}$ and permeabilized with $0.5 \%$ Triton X-100 in PBS for 10 min for IGF-1R staining to evaluate the differences in protein conformations of IGF-1R. Subsequently, 5\% goat serum was used to block the cells for $1 \mathrm{~h}$, and the primary antibody against IGF-1R (1:80, Abcam, United States) was used to incubate the cells overnight at $4^{\circ} \mathrm{C}$. On the following day, an FITC-labeled secondary antibody (1:100, Bioworld, United States) was used to incubate the cells for $1 \mathrm{~h}$ in the dark. The fluorescence intensity of a population of 10,000 cells was measured with the fluorescence associated with the FITC. IgG-treated cells were used as negative controls (Fung et al., 2014).

Subsequently, $5 \%$ goat serum was used to block the cells for $1 \mathrm{~h}$, and the primary antibody against IGF-1R (1:80, Abcam, United States) was used to incubate the cells overnight at $4^{\circ} \mathrm{C}$. On the following day, an FITC-labeled secondary antibody (1:100, Bioworld, United States) was used to incubate the cells for $1 \mathrm{~h}$ in the dark. The fluorescence intensity of a population of 10,000 cells was measured with the fluorescence associated with FITC. IgG-treated cells were used as negative controls.

\section{Statistics Analysis}

All experimental results are presented as the mean \pm SEM of at least three independent experiments. One-way or twoway ANOVA was used to test statistical differences among groups. All statistical analyses were performed using GraphPad Prism 6.0. Differences were considered significant at $p<0.05$ $\left({ }^{*} p<0.05,{ }^{* *} p<0.01\right)$.

\section{RESULTS}

\section{Generation of Igf1r-Knockout MC3T3-E1 Clones}

Four homozygous mutations (c.931G > C, c.1507T > G, c. $1762 \mathrm{C}>\mathrm{T}$, and c.2269 T > C) in the CDS of IGF-1R ECD from 
pigs of different body size traits were all synonymous mutations (Figure 1A). Two haplotypes, of which GTCT is the haplotype of $\mathrm{BM}$ pigs and CGTC is that of large pigs, were formed (Figure 1B).

To investigate the role of different $I g f 1 r$ haplotypes in bone development and avoid endogenous Igf1r interference in osteoblasts, we first constructed Igf1r-knockout in MC3T3-E1 cells by using the CRISPR/cas9 system. To ensure complete Igf1r knockout, we designed one target site on the exon 4 of $I g f 1 r$ sequences to target the common sequences contained in all the alternative splicing isoforms. The position of the target site was relatively close to the beginning of the sequence (Figure 1C). sgRNA sequences were then connected to plasmid PX458 and transfected into MC3T3-E1 cells. Fluorescence-activated cell sorting was implemented to select the cells expressing GFP fluorescence to improve the efficiency of positive cloning screening. The presence of IGF-1R mutations in genomic DNA was identified via DNA sequencing. Most cell clones showed frameshift mutation, and one cell clone had a nucleotide deletion near the protospacer adjacent motif (Figure 1C). To assess knockout efficiency, we performed immunofluorescence staining on the Igf1r $r^{\text {Knockout }}$ cell clones by using the IGF-1R antibody. The MC3T3-E1 cells exhibited strong IGF-1R signals, whereas the Igf1r Knockout cell clones lost the IGF-1R signal (Figure 1D). Meanwhile, the IGF-1R protein levels in different mutant clones were measured via immunoblotting. The Igf1r Knockout cell clones lost the IGF-1R protein expression as indicated by the Western blot results (Figures 1E,F). We selected a clone with sufficient Igf1r knockout and named MC3T3-knockout cell.

\section{Stable Expression of Two Haplotypes of Igf1r in MC3T3-KO Cells}

The pB513B-LP and pB513B-BM vectors were co-transfected with the $\mathrm{PB}$ transposase expression plasmid into MC3T3-KO cells, respectively, and normal MC3T3-KO cells were used as a control. The co-transfected cells were selected by puromycin for 10 days to obtain puromycin-resistant cell clones. About 50 cell clones per well were left after the co-transfection of the screened PB dual vector system. Almost no cell clones survived in the control group, indicating that the cell clones that survived puromycin selection were positively transposed cell clones.

Genomic DNA was extracted from transposed MC3T3$\mathrm{KO}$ cells and MC3T3-KO control cells to evaluate whether exogenous genes had been stably integrated into the genome. The expression level of exogenous genes was then detected. Specific PCR products corresponding to the two haplotypes of Igf1r sequences were observed from the transposed cells, whereas no PCR products were found from the control cells without transposed cells. qPCR was performed to detect the two integrated haplotypes of Igf1r gene copy number and analyze 10 clonal cell lines for each haplotype. The cell clones had 3-13 copies with an average of five copies per clone. We finally selected two cell clones with haplotypes of five copies each. The copy number of our clones was similar to that reported by previous studies in which mammalian cells were transfected with the PB transposon system (Ding et al., 2005; Grabundzija et al., 2010). Finally, puromycin-resistant cell clones with two different strong
IGF-1R signals were observed via immunofluorescence staining (Figure 2A). These cell clones were named as MC3T3-LP cells (LP group) and MC3T3-BM cells (BM group).

\section{Effects of Two Haplotypes of Igf1r on the IGF-1R mRNA and Protein Expression Level}

The expression levels of IGF-1R in MC3T3-LP cells containing the CGTC haplotype and MC3T3-BM cells containing the GTCT haplotype were detected to clarify the biological effects of these haplotypes. A reverse primer was designed on the FLAG tag sequences to avoid the interference of intracellular IGF-1R in detecting the mRNA expression level (Figure 2B). The mRNA expression levels were significantly lower in the BM group than in the LP group (Figure 2C) $(P<0.01)$. The protein expression level of each group was detected using an anti-IGF-1R antibody (Figures 2D,E) $(P<0.01)$ and anti-FLAG tag antibody (Figures 2F,G) $(P<0.01)$. Results consistently showed that the mRNA and protein expression levels of the BM group were lower than those of the LP group. Given that changes in expression levels can affect the biological effects of genes, we speculated that different haplotypes of Igf1r may also affect its function based on the observed differences in expression levels.

\section{Effect of Two Haplotypes of Igf1r on Cell Proliferation}

To verify the functions of IGF-1R ECD encoded by the haplotypes in Bama Xiang and large pigs, we investigated the cell proliferation abilities of MC3T3-LP and MC3T3-BM cells and compared them with that of MC3T3-KO cells. CCK- 8 assay revealed that the cell proliferation ability of the LP group was more substantial than that of the $\mathrm{BM}$ and $\mathrm{KO}$ groups from 0 to $72 \mathrm{~h}$ (Figure 3) $(p<0.01)$, suggesting that the cells of the BM group had a lower growth potential than the cells of the LP groups.

\section{Effect of Two Haplotypes of Igf1r on the ALP Activity of Osteoblasts}

The proliferation and differentiation of osteoblasts are essential factors in bone growth. On the basis of our observations of the effects of cell proliferation, we further detected the effects of different haplotypes of Igf1r on osteoblast differentiation. ALP activity is a marker of early osteogenic differentiation that is used to evaluate the effects of different Igf1r haplotypes on cell differentiation (Golub et al., 1992; Bancroft et al., 2002; Hosseini et al., 2019). The MC3T3-LP, MC3T3-BM, and MC3T3-KO cells were maintained in a differentiation medium. The ALP activities of the LP, BM, and $\mathrm{KO}$ groups were separately measured on days $3,5,7,9,14$, and 21. As shown in Figure 4A, the ALP activities of all three groups fluctuated: the trend initially fell and then rose from day 3 to day 21. Meanwhile, the ALP activity of the BM group was significantly higher than that of the LP and KO groups from day 3 to day $7(P<0.01)$. Thereafter, the ALP activity of the LP group was significantly higher than that of the MC3T3BM and MC3T3-KO groups $(P<0.01)$. Compared with the LP group, the BM group promoted ALP activity at the early stage of 


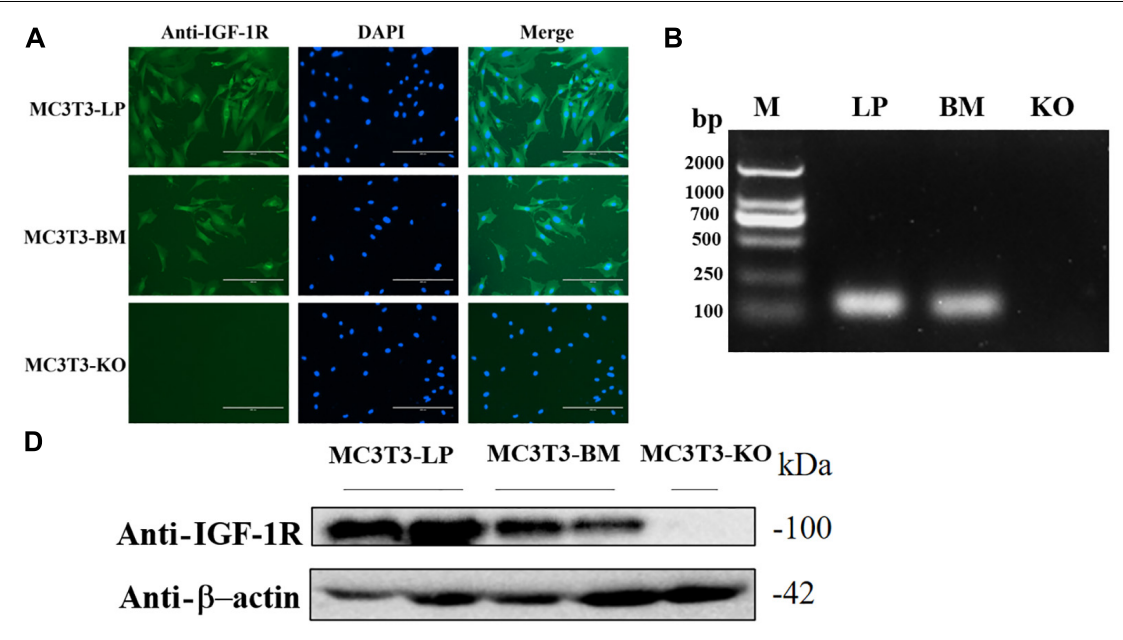

C
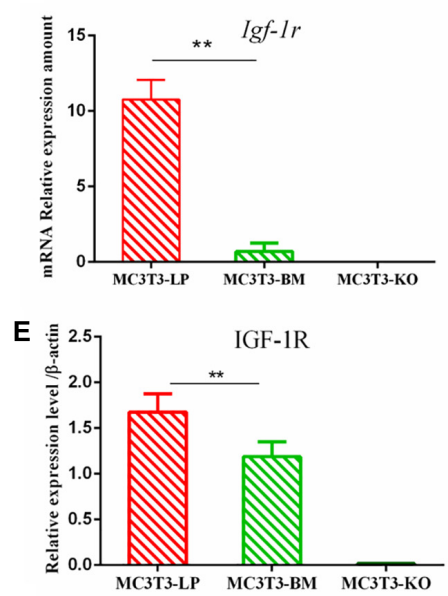

$\mathbf{F}$

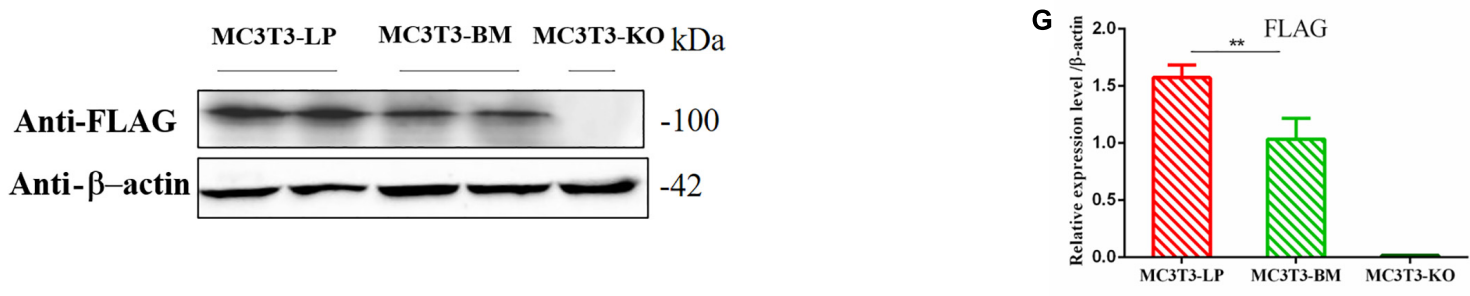

FIGURE 2 | Generation of recombinant cell lines of two haplotypes of lgf1r and effect of the haplotypes of lgf1r on gene transcription, translation.

(A) Immunostaining of IGF-1R (Green) and DAPI (Cyan) in MC3T3-LP and MC3T3-BM cells. (B) PCR results of the MC3T3-LP (LP), MC3T3-BM(BM) and MC3T3-KO (KO)cells. (C) RT-qPCR analysis of IGF-1R expression in MC3T3-LP, MC3T3-BM and MC3T3-KO cells. (D,F) Western blot analysis of the IGF-1R and FLAG expression in MC3T3-LP, MC3T3-BM and MC3T3-KO cells and identified with anti-IGF-1R and anti-FLAG antibodies, respectively. (E,G) Quantification of the (D,F) western blot results, respectively $\left({ }^{\star \star} p<0.01\right)$.

differentiation but significantly inhibited ALP activity at the late stage of differentiation. However, the detection of ALP activity alone was insufficient to prove that the different haplotypes of Igf1r affected osteoblast differentiation as this process is regulated by numerous genes and transcription factors. We speculated that the haplotypes of IgfIr may affect the expression of genes related to bone differentiation.

\section{Effect of the Two Haplotypes of Igf1r on the Expression of Genes Related to Osteogenic Differentiation}

We explored how the genotypes of Igf1r affect osteogenic differentiation. We investigated the expression of the genes related to osteogenic differentiation in the BM, LP, and $\mathrm{KO}$ groups. The expression levels of collagen-1 (Col-1), osteocalcin $(O c n)$, osterix $(O s x)$, osteopontin $(O p n)$, runt-related transcription factor 2 (Runx2), and $A l p$ were significantly different in the cells carrying the two haplotypes of Igflr. On the 7th day of differentiation, the mRNA expression level of $\mathrm{Col}$ 1 and ALP was lower in the KO and LP groups than that in the LP group (Figures 4B,C) $(P<0.01)$. However, the mRNA expression level of Opn, Ocn, Runx2, and Osx were higher in the LP group than that in the KO and BM groups on days 7, 14, and 21 (Figures 4D-G) $(P<0.01)$.
Col-1 induces extracellular matrix formation at the early stages of osteocyte differentiation, whereas Opn acts as a mediator of mineralization (Chai et al., 2019; Hosseini et al., 2019). The expression levels of these two genes play a crucial role in osteoblast differentiation. Western blot revealed that the expression level of Col-1 was higher in the BM group than that in

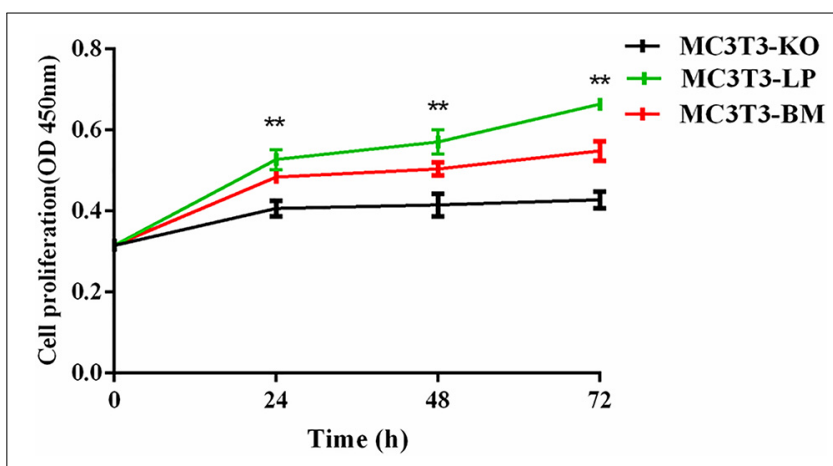

FIGURE 3 | Effect of two haplotypes of Igf1r on cell proliferation in MC3T3-LP, MC3T3-BM and MC3T3-KO cells, CCK-8 proliferation assay of MC3T3-LP, MC3T3-BM and MC3T3-KO cells after starved in DMEM containing 3\% FBS for $3 \mathrm{~h}$ at $0,24,48$, and $72 \mathrm{~h}\left({ }^{* \star} \mathrm{P}<0.01\right)$. 
A

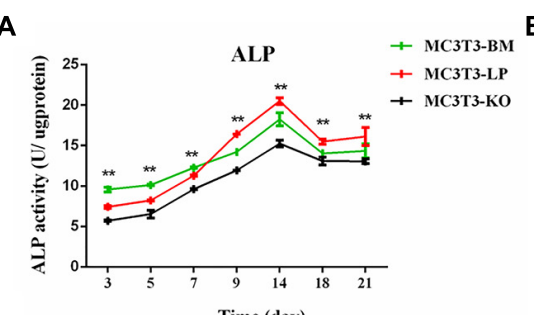

D

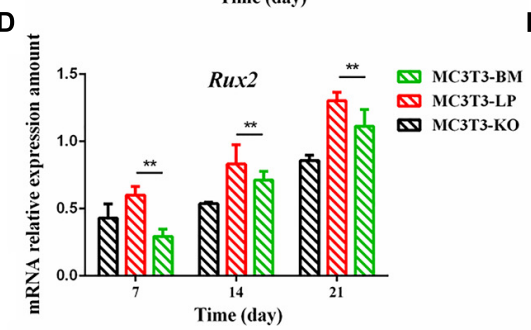

$\mathbf{F}$

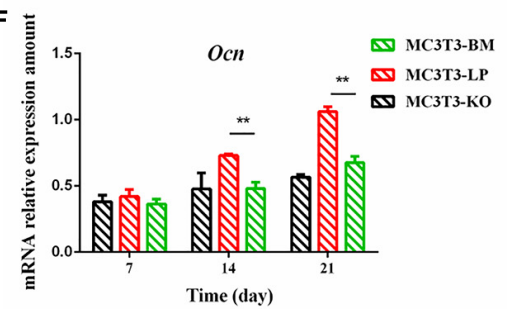

B

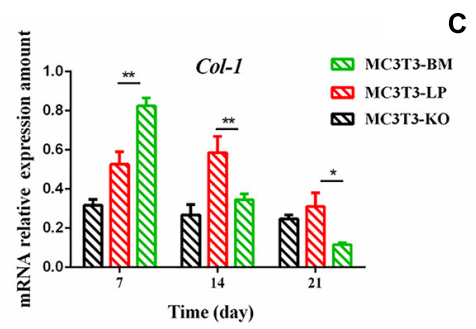

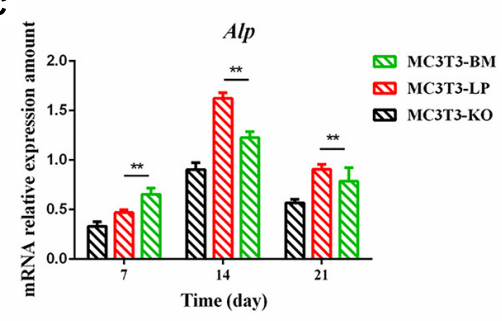

E

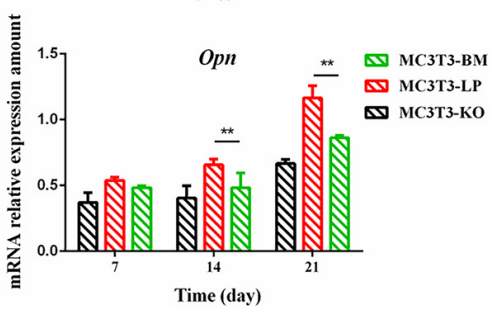

G

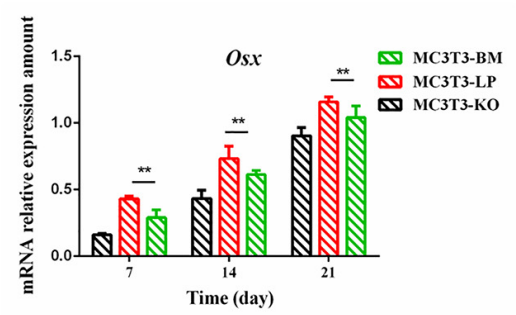

FIGURE 4 | Effect of two haplotypes of Igf1r on ALP activity and the mRNA amount of differentiation related gene in MC3T3-LP, MC3T3-BM and MC3T3-KO cells. (A) ALP activity assay of MC3T3-LP, MC3T3-BM and MC3T3-KO cells on days 7, 14 and 21, respectively. (B-G) RT-qPCR analysis of Col-1, ALP, Runx2, Opn, Ocn and Osx expression levels in MC3T3-LP, MC3T3-BM and MC3T3-KO cells on days 7, 14, and 21, respectively $\left({ }^{\star} P<0.01\right)$.

the LP group on days 1 and 2 but lower from days 3 to $6(P<0.01)$ (Figures 5A,C). Furthermore, the protein expression level of OPN was markedly attenuated in the BM group compared with that in the LP group from days 3 to 21 (Figures 5B,D) $(P<0.01)$. These results were consistent with the results described in the preceding section.

\section{Effects of the Two Haplotypes of Igfir on Mineralized Nodules}

Calcium deposition is an important indicator of matrix mineralization in bone differentiation. AR, which preferentially chelates with calcium ions, is widely used to identify matrix mineralization (Puchtler et al., 1969). A previous study indicated that the mineralization of MC3T3-E1 cells occurs in a timedependent manner and can be examined during osteoblast differentiation for up to 21 days (Xi et al., 2016). The initial formation of mineralized nodules was observed on day 7 . The mineralized nodules gradually increased with the extension of culture time and degree of differentiation. After induction of osteoblast mineralization, ARS revealed that the BM group had slightly less mineralized nodules compared with the LP and KO groups on day 7 . The modules were remarkably larger in the LP group than those in the BM and $\mathrm{KO}$ groups on days 14 and 21 (Figures 6A,B) $(P<0.01)$. The results suggested that the $\mathrm{BM}$ group promoted the early stage of osteogenic mineralization, whereas the LP group promoted the late stage of osteogenic mineralization. Both groups exhibited similar trend in terms of the expression levels of genes related to osteogenic differentiation. On the basis of osteogenic differentiation, we observed that the regulation of the haplotypes of $I g f 1 r$ were different at various stages of differentiation. We speculated that the haplotypes of Igf1r may affect the expression of genes related to bone development by affecting the signaling pathways associated with intracellular osteogenic differentiation.

\section{Effects of the Two Haplotypes of Igf1r on the Signal Output of Osteogenic Differentiation}

Induction of autophagy is required in early differentiation, and the binding of IGF-IR with IGF-1 can activate different AMPK phosphorylation sites at different stages of cell differentiation to regulate autophagy stimulation or inhibition (Xi et al., 2016). Given that phosphorylation of AMPK-T172 directly phosphorylates unc-51-like autophagy-activating kinase-1 S555 (ULK-1 S555), we compared the phosphorylation of AMPKT172 and ULK-1 S555 and the expression level of Beclin1 (another critical component of autophagosomes) at the early stage of differentiation. Given that the late activation of mTOR S2448/AKT S473/AMPK S485 occurs in the osteogenic differentiation of human mesenchymal stem cells and MC3T3-E1 cells (Pantovic et al., 2013; Xi et al., 2016), we then detected 


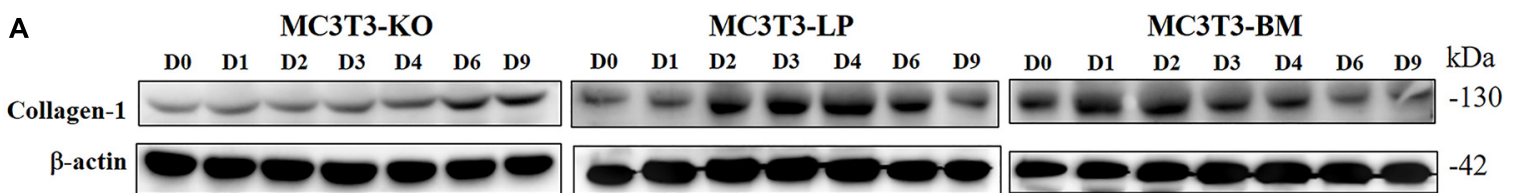

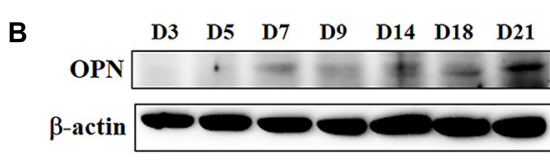

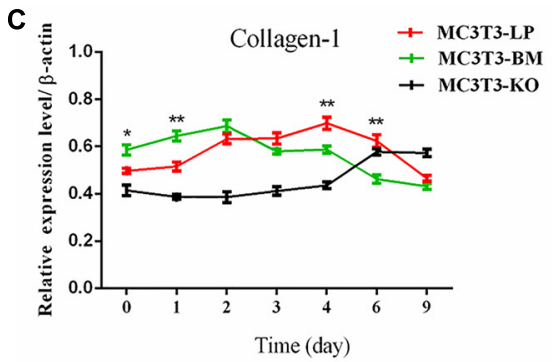

$\begin{array}{lllllllllllllll}\text { D3 } & \text { D5 } & \text { D7 } & \text { D9 } & \text { D14 } & \text { D18 } & \text { D21 } & \text { D3 } & \text { D5 } & \text { D7 } & \text { D9 } & \text { D14 } & \text { D18 } & \text { D21 } & \mathrm{kDa}\end{array}$

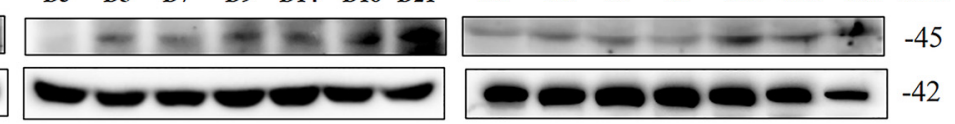

D

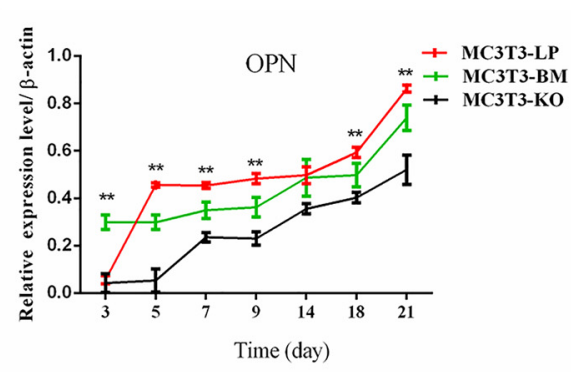

FIGURE 5 | Effect of two haplotypes of Igf1r on the protein amount Col-1 and OPN. (A) Western blot analysis of Col-1 expression in MC3T3-LP, MC3T3-BM and MC3T3-KO cells on days 0, 1, 2, 3, 4, 6, and 9. (B) Western blot analysis of OPN expression in MC3T3-LP, MC3T3-BM and MC3T3-KO cells on days 3, 5, 7, 9, 14, 18 and 21. (C) The line chart of the (A) after a gray scale analysis. (D) The line chart of the (B) after a gray scale analysis $\left({ }^{\star} P<0.05,{ }^{\star \star} P<0.01\right)$.

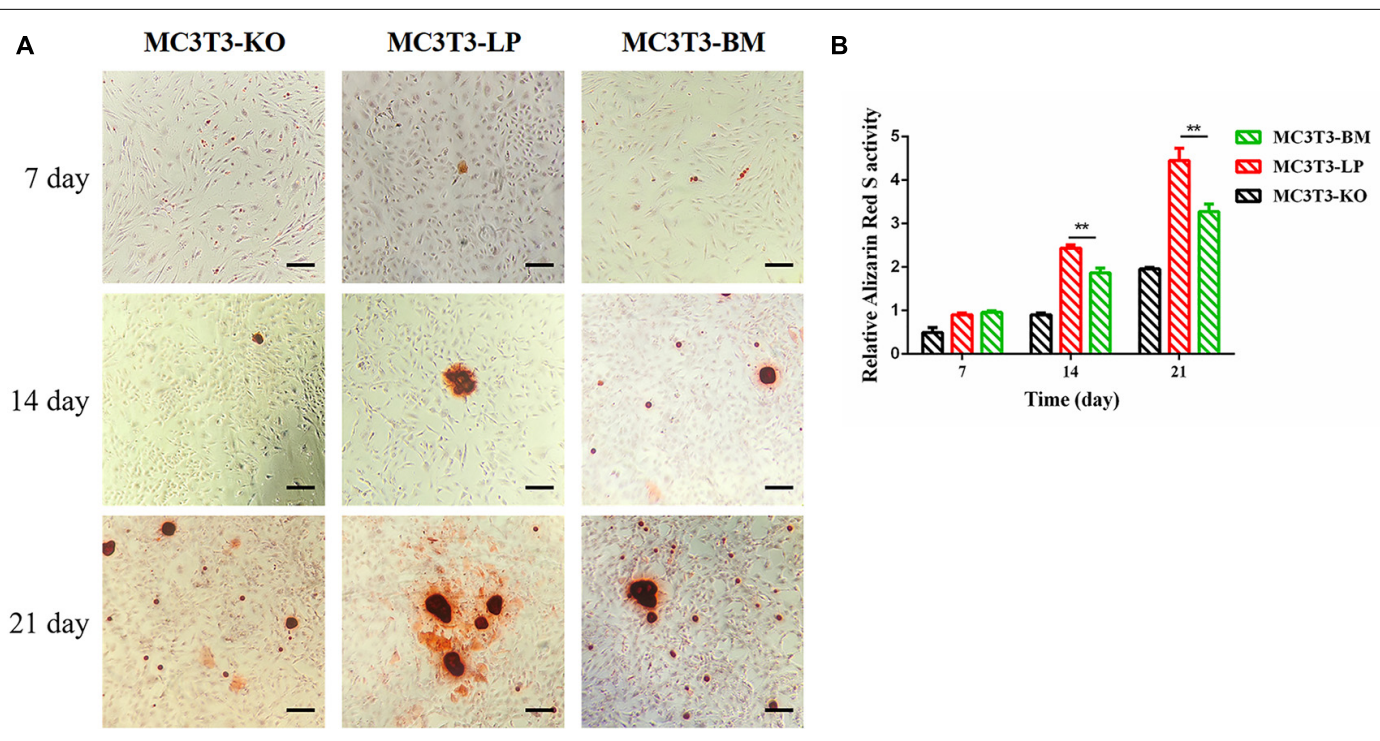

FIGURE 6 | Effect of two haplotypes of Igf1r on cell mineralization in MC3T3-LP, MC3T3-BM and MC3T3-KO cells. (A) Mineralized nodules of MC3T3-LP, MC3T3-BM and MC3T3-KO cells on days 7, 14, and 21. The images were captured on the inverted phase microscope (scale bar, 200 $\mu \mathrm{m})$. (B) The quantified result of mineralization by $10 \%$ cetylpyridinium chloride $\left({ }^{\star \star} P<0.01\right)$.

the phosphorylation levels of mTOR S2448, AKT S473, and AMPK S485 at the late stage of differentiation. AMPK-T172 phosphorylation level and Beclin-1 expression level initially increased in the $\mathrm{BM}$ group from day 0 to 2 , but the phosphorylation level of ULK-1 S555 was not significantly different. Moreover, Beclin-1 expression level and AMPK-T172 and ULK-1 S555 phosphorylation levels evidently decreased in the $\mathrm{BM}$ group compared with those in the LP group from day 3 to 9 (Figure 7). However, at the relatively late stage of differentiation, mTOR S2448, AKT S473, and AMPK S485 phosphorylation levels in the BM group continued to decrease from day 3 to 21 (Figure 8).

These results suggested that the two haplotypes of Igfir play different roles in regulating the downstream signaling pathway of osteoblast differentiation. The osteoblasts in the BM group had a higher AMPK phosphorylation level and Beclin-1 


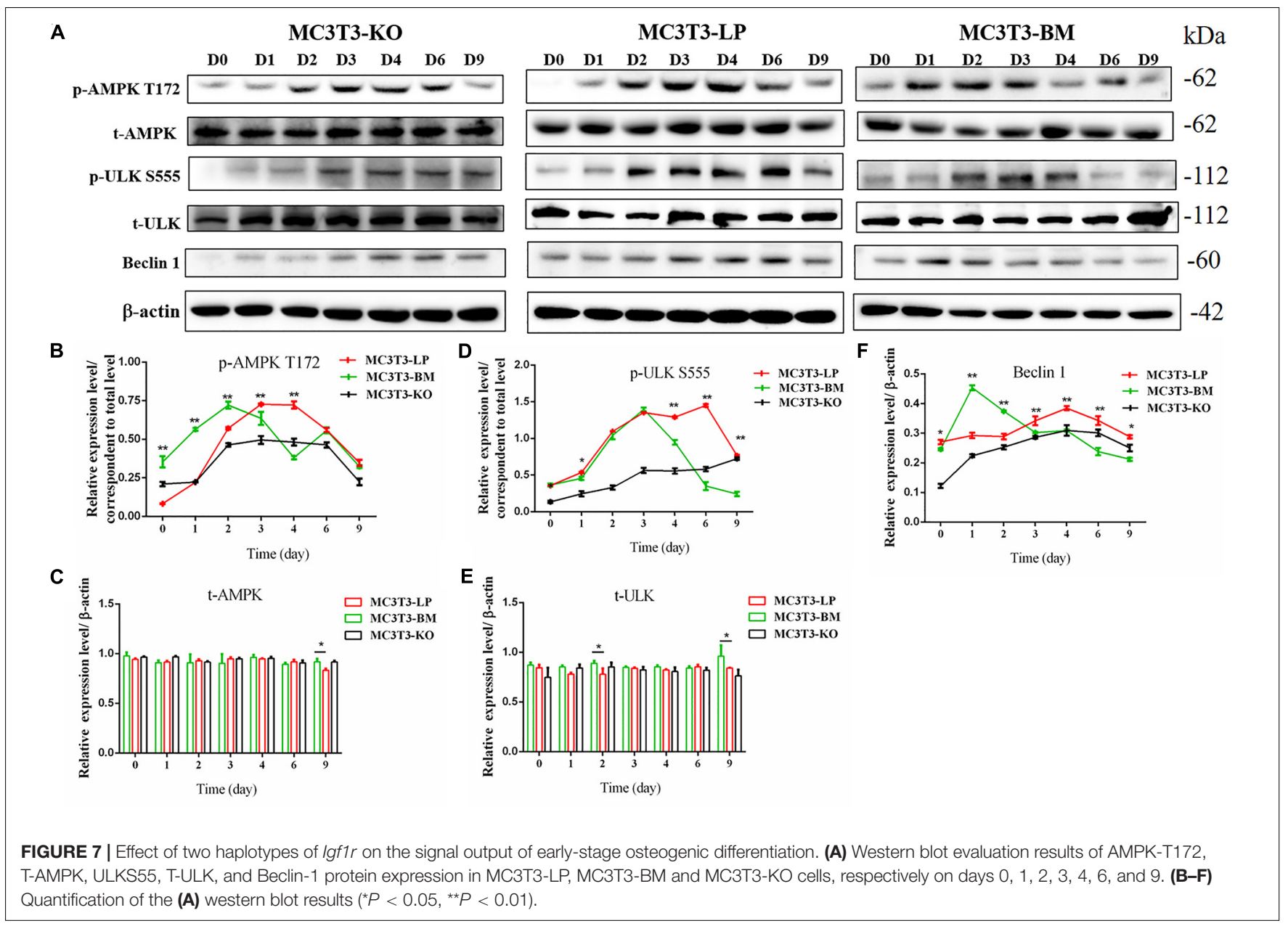

expression level compared with the LP group at the early stage of differentiation, and the osteoblasts inhibited autophagy from the third day of differentiation.

\section{Effects of the Two Haplotypes of Igf1r on mRNA and Protein Stability}

Synonymous mutations can affect gene expressions by affecting gene stability and translation folding (Hunt et al., 2014; Cheng et al., 2018). We speculated that the haplotypes of Igf1r may be influenced by differences in mRNA and protein stability. On the basis of the differences in the expression level of Igf1r in the $\mathrm{BM}$ and LP groups at the transcription and translation levels (Figures 2D,E,G), we evaluated the differences in mRNA and protein structural stabilities between the two haplotypes of Igflr. The secondary mRNA structures and minimum free energies of the two haplotypes of Igf1r ECD were predicted through the bioinformatics website RNAfold web server. Results showed that the secondary mRNA structures of the two haplotypes of Igf1r ECD were different, and the minimum free energy increased by $6.8 \mathrm{kcal}$ when the GTCT haplotype carried by the BM group was converted to the CGTC haplotype carried by the LP group (Figures 9A,B). In combination with these results and the differences in the expression levels of the two haplotypes of $I g f 1 r$ previously detected, we speculated that these haplotypes may regulate gene expression levels on the basis of theory of codon translation efficiency. In other words, the translation rates of individual codons might vary by 5 - to 25 -fold (Curran and Yarus, 1989; Srensen and Pedersen, 1991). Another study reported that stabilization by a mutation of the initiator helix by $-3.6 \mathrm{kcal} / \mathrm{mol}$ resulted a 500-fold drop in expression (Smit and Duin, 1990).

We examined the mRNA stability of the two haplotypes. The MC3T3-LP and MC3T3-BM cells were treated with the mRNA transcription inhibitor ActD, respectively. Results showed that the mRNA stability of Igf1r in the MC3T3-BM cells was higher than that in the MC3T3-LP cells $(P<0.01)$ (Figure 9C). This result was consistent with the prediction outcomes of mRNA secondary structures. Meanwhile, the protein stability test results showed that the IGF-1R protein degradation in MC3T3-BM cells was more slowly than that in MC3T3-LP cells $(P<0.01)$ (Figures 9D,E).

\section{Different Igf1r Haplotypes Alter Binding Affinity With IGF-1}

Considering that the four synonymous mutations on IGF-1R ECD are located near the binding site with the ligand IGF1 , we detected the interactions between IGF-1 and IGF-1R 


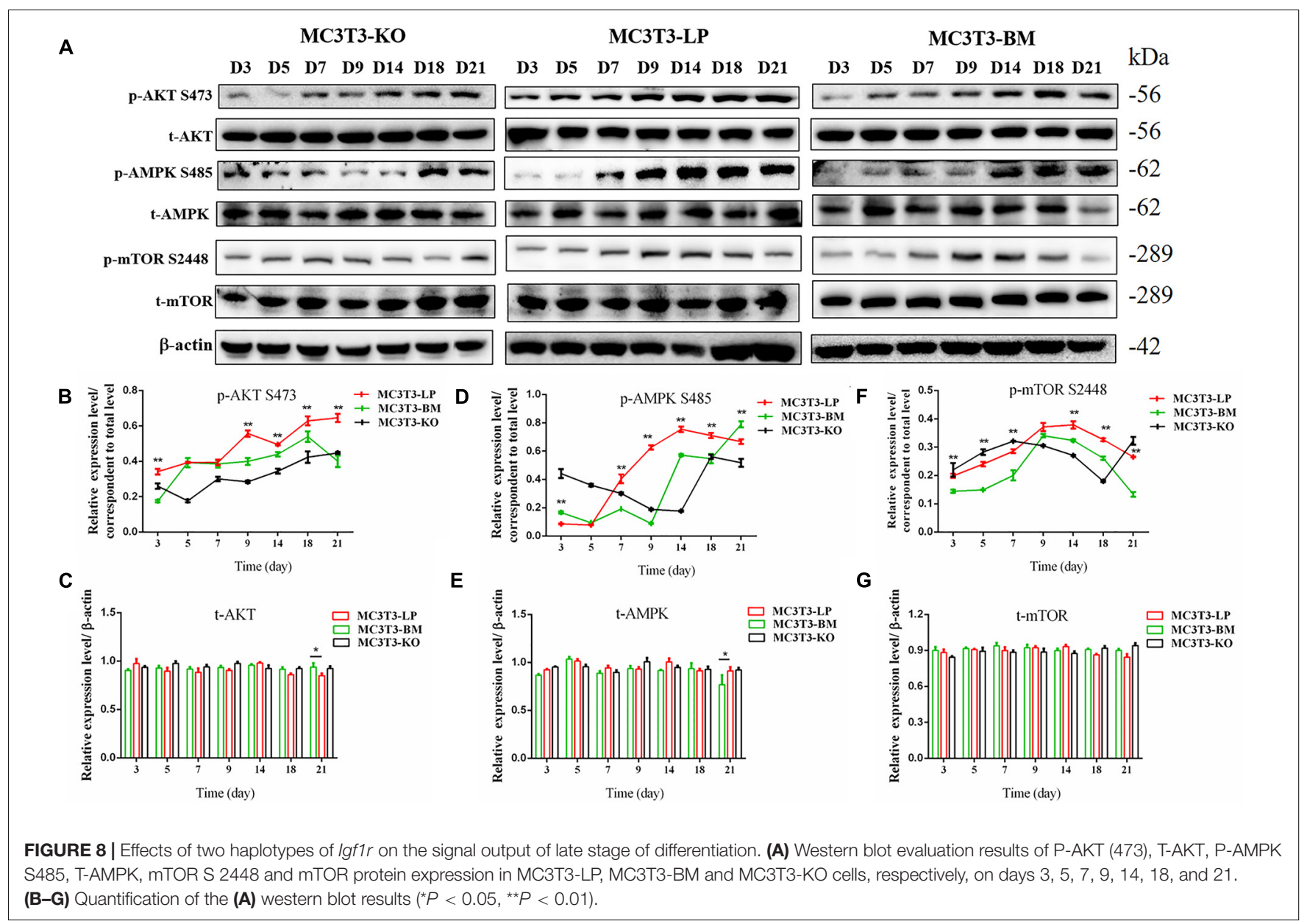

in MC3T3-LP, MC3T3-BM, and MC3T3-KO cells via coimmunoprecipitation assay. As shown in Figure 10, except that IGF1R was not expressed in MC3T3KO cells, different amounts of IGF-1 and IGF-1R were the inputs of MC3T3-LP, MC3T3-BM and MC3T3-KO cells (Figures 10A,B) $(P<0.01)$. Additionally, IGF-1 was co-immunoprecipitated with IGF-1R when it was immunoprecipitated by the IGF-1R antibody (Figure 10A). No binding was detected between IGF-1 and IGF-1R in MC3T3$\mathrm{KO}$ cells, excluding the interference of non-specific binding, and compared with IGF-1 in the input, the amount of IGF-1 that bound with IGF-1R in the MC3T3-LP cells was higher than that in the MC3T3-BM cells (Figure 10C) $(P<0.01)$. The difference in the binding rate between IGF-1R and IGF-1 can be influenced by several factors, such as the expression of IGF-1R on cell surfaces and the conformation of IGF-1R proteins. Thus, we detected the expression level of IGF-1R on the surface of cell membranes and the conformation of IGF-1R proteins.

\section{Effect of the Two Haplotypes of Igf1r on Membrane Surface Expression and Protein Conformation}

To determine the reasons for the decrease in affinity of the two haplotypes of Igflr with IGF-1, we detected IGF-1R distributions across the MC3T3-LP, MC3T3-BM and MC3T3KO cell membranes by using the anti-FLAG antibody. The expression of IGF-1R on cell membrane surface in fixed and non-permeabilized cells and the expression of total IGF-1R in fixed and permeabilized cells were quantitatively detected via flow cytometry. Almost no fluorescence was detected in MC3T3-KO cells. Excluding the interference of non-specific binding, the total protein and IGF-1R expression levels on the surfaces of cell membranes were lower in the BM group than those in the LP group (Figures 11A-C) $(p<0.01)$. Moreover, the relative membranal expression level of IGF$1 \mathrm{R}$ was lower in the BM group than that in the LP group (Figure 11D) $(p<0.01)$.

Monitoring the antigen-antibody interaction of a protein in an intact cell by using flow cytometry has the considerable advantage of allowing a conformation-sensitive antibody to explore the tertiary structure of a functional protein in its native environment (Sauna et al., 2009). To determine whether the four synonymous mutations of Igf1r in ECD changed their protein conformations, we incubated the MC3T3-LP and MC3T3-BM and MC3T3-KO cells with the IGF-1R antibody, the KO group as a negative control group. We detected the fluorescence intensity of each haplotype by using a flow cytometer to reflect the binding rate between IGF-1R and its antibody. The distribution 
A

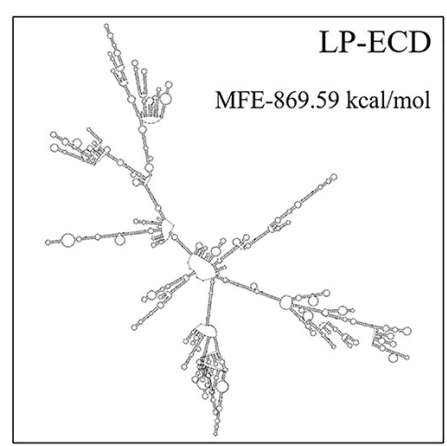

D

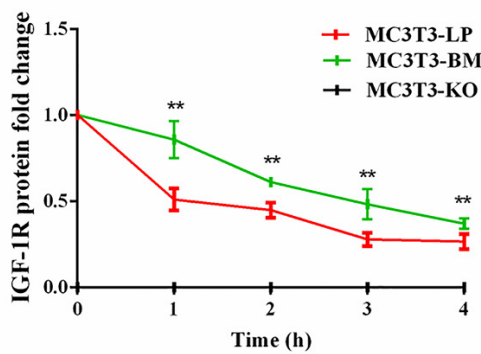

B

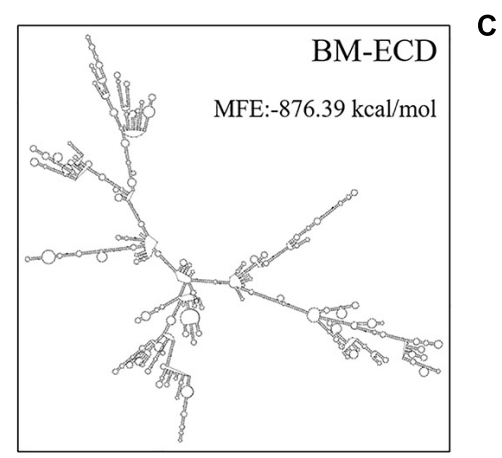

$\mathbf{E}$

C

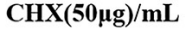

Anti-FLAG

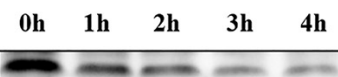

Anti- $\beta$-actin

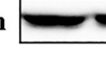

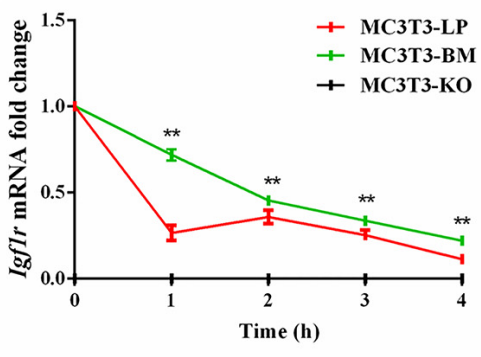

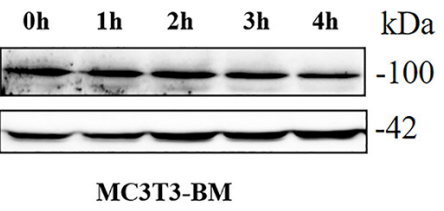

FIGURE 9 | The effect of two haplotypes of Igf1r on the stability of mRNA and protein $\mathbf{( A , B )}$ mRNA secondary structure and minimum free energy of two haplotypes of Igf1r ECD cDNA sequence from large pig and Bama Xiang pig. (C) MC3T3-LP and MC3T3-BM cells were treated with ActD for 0-4 h. The level of IGF-1R was analyzed. (D) MC3T3-LP and MC3T3-BM cells were treated CHX for 0-4 h. The level of IGF-1R was analyzed by western blot and $\beta$-actin was used as a loading control. (E) Line chart of the (D) after the gray scale analysis ( ${ }^{\star \star} P<0.01$ ).

of fluorescence intensity in a population of 10,000 cells is shown in Figure 10E. The cells treated with the IgG antibody established a baseline with a low level of fluorescence that intuitively represented non-specific interactions and interactions with the secondary antibody alone. The fluorescence intensity of the binding of MC3T3-KO cells to the antibody was similar to that of IgG antibody, which could exclude the endogenous interference of MC3T3-KO cells. In addition, the MC3T3-LP and MC3T3-BM cells exhibited specific binding to the Igflr antibody. The MC3T3-LP cells showed a higher increase in fluorescence than the MC3T3-BM cells, indicating that the Igflr haplotypes of large pigs have a more remarkable affinity with the antibody than the Igfir haplotypes of Bama Xiang pigs. Thus, the two haplotypes of Igfir generated by the four synonymous mutations affected the membrane surface expression and protein conformation of IGF-1R.

\section{DISCUSSION}

Miniature pigs have likely become important laboratory animals and xenotransplantation donors in biomedical research (Prather et al., 2013). However, the formation of miniature pigs remains unclear. IGF-1R is composed of seven extracellular domains, namely, L1, CR, L2, Fn1, Fn2, ID, and Fn3, as well as a transmembrane (TM) region and an intracellular domain (Baxter, 2015). The L1, ID, and Fn3 domains are the key regions where IGF-1R binds with IGF-1 (Adams et al., 2000). A previous study demonstrated that the five synonymous mutations of IGF-1R ICD affect cell proliferation and alter kinase activity (Wang et al., 2020). By contrast, in the present study, we discussed the four synonymous mutations identified in the IGF1R ECD of large and miniature pigs. These mutations were located at the CR, Fn1, and ID structural domains of IGF-1R, as well as near the IGF-1 binding domains. IGF-1R, activated by IGF-1, mediates a conserved signaling pathway necessary for stimulating osteoblast proliferation (LeRoith et al., 1995), thereby accelerating their differentiation and enhancing bone matrix production (Xi et al., 2016). Loss of IGF-1R leads to severe growth deficiency and developmental delays in ossification (Baker et al., 1993). Mice with targeted IGF-1R overexpression in osteoblasts exhibit an increased bone formation rate and an enhanced trabecular and cortical bone volume (Zhao et al., 2000). Numerous studies demonstrated that synonymous mutations have considerable biological effects on various processes, such as gene expression, gene stability, and protein conformation (Fung et al., 2014; Chaney and Clark, 2015; Cheng et al., 2018). As a ligand-dependent receptor, stability and conformational changes in IGF-1R regulate IGF-1R activity and lead to differences in downstream functions. Moreover, previous studies corroborated the relationship between gene SNPs and bone phenotypes in animals (Horvath et al., 2016; Bin et al., 2017; Gaffney-Stomberg et al., 2017). Therefore, we suspected that these synonymous mutations of porcine IGF-1R ECD most likely play a vital role in regulating IGF-1R expression, as well as in the regulation of the proliferation, differentiation, and mineralization of osteoblasts. 

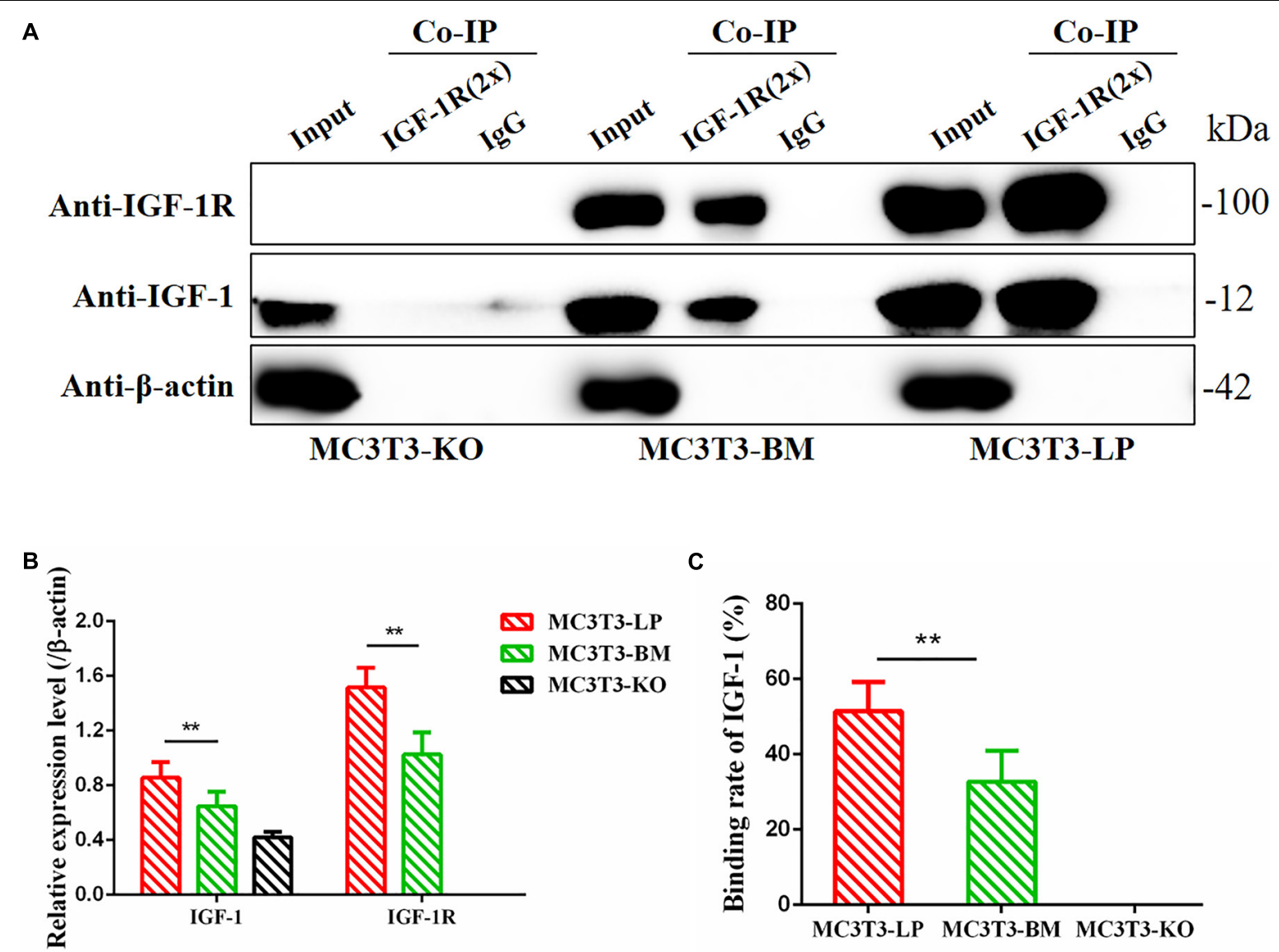

FIGURE 10 | Binding affinity analysis of the IGF-1 with IGF-1R in MC3T3-KO, MС3T3-BM and MC3T3-LP cells (A) MC3T3-KO cells (the KO group), MC3T3-BM cells (GTCT haplotype of BM group) and MC3T3-LP cells (CGTC haplotype of LP group) were lysed, IGF-1R was immunoprecipitated and lgG served as a negative control, IGF-1 and IGF-1R were then examined by western blot. (B) Quantification of IGF-1 and IGF-1R levels in the immunoprecipitated complex. (C) Quantification of the related binding rate with IGF-1 $\left({ }^{\star *} P<0.01\right)$.

We first investigated the effects of two Igflr haplotypes formed by four linkage synonymous mutations on gene expression. The results were consistent with our expectations, indicating that the expression levels in the BM group were lower than those in the LP group at both the transcription and translation levels. We observed different effects of the two Igfir haplotypes on promoting cell proliferation. The KO group had the lowest proliferation capacity, thus indirectly indicating that IGF-1R plays an important role in cell proliferation. Furthermore, the LP group had a better effect on promoting cell proliferation than the BM group. These results suggested that the preferred codons in large pigs are more conducive to cell proliferation and survival. Moreover, the four synonymous mutations of porcine Igfir ECD may contribute to the formation of body size in animals.

We also found that IGF-1R is involved in the regulation of osteoblast differentiation and mineralization. Among the indicators of cell differentiation, ALP activity is considered one of the most essential factors affecting osteoblast differentiation (Whyte, 1994). ALP generates calcium phosphate to be deposited in mature osteoblasts and contributes to bone mineralization (Orimo and Shimada, 2008; Hosseini et al., 2019). Aside from
ALP activity, the expression levels of genes related to osteogenic differentiation (Col-1, Alp, Opn, Ocn, Rux2, and Osx) were also found to be important factors for evaluating cell differentiation. Col-1 and Alp induce the formation of the primary extracellular matrix (ECM) at the early stage of differentiation (Hosseini et al., 2019). The early differentiation of pre-osteoblasts is regulated by Runx2 (Ducy et al., 1997). Runx2 and Osx play a regulative role in regulating osteoblast differentiation and bone formation in growing bones (Baek et al., 2009). Ocn is a marker at the late stage of osteoblast differentiation (Hosseini et al., 2019). Opn is a highly phosphorylated glycoprotein secreted during osteoblast differentiation and differentiation, the expression level of which gradually increases from days 7 to 21 (Letzring et al., 2010; Wei et al., 2020). Hence, Opn can be used as an indicator of the intermediate and late stages of differentiation. These genes play an essential role in regulating osteoblast differentiation and bone formation in growing bones. A previous study reported that the expression of Col-1 increases at the early stage and then decreases at the later stage of differentiation (Hosseini et al., 2019; Wei et al., 2020). The expression level of Opn continues to increase on the 7th day of differentiation (Wei et al., 2020). 


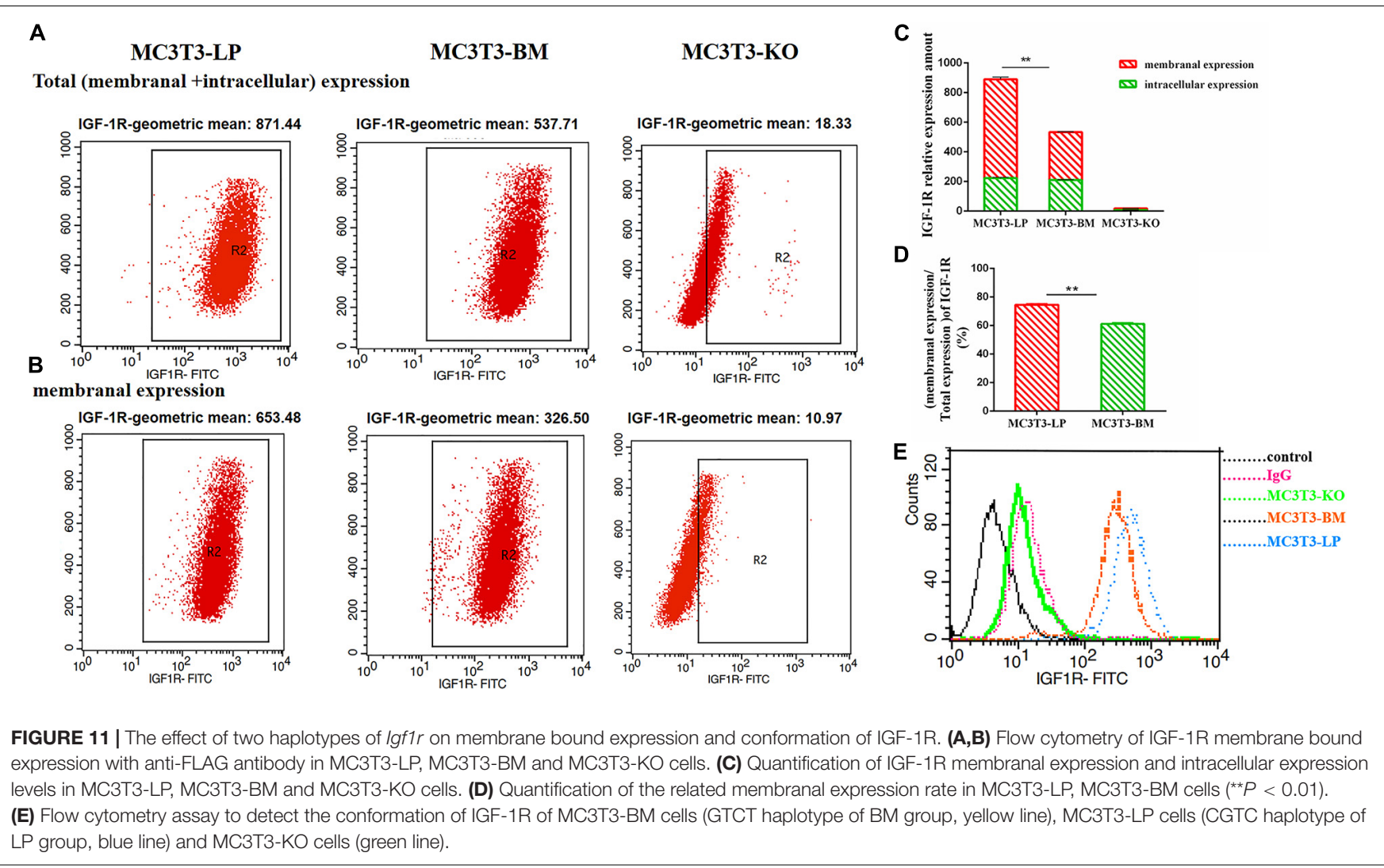

On the basis of these reports, we selected Col-1 and Opn as the indicators of early and late differentiation stages, respectively, for follow-up studies.

The ALP activity of the LP and BM groups was substantially higher than that of the KO. The BM group promoted the early stage of osteogenic differentiation, whereas the LP group promoted the late stage of osteogenic differentiation. This observation was further confirmed by the detection of the expression levels of genes related to osteogenic differentiation. Matrix mineralization is the final step in osteoblast differentiation. It marks osteogenic maturation ability and plays a crucial role in regulating bone size (i.e., bone mass and volume). AR stains are widely used to detect mineral deposition (Puchtler et al., 1969). In this study, the number of mineralized nodules was substantially greater in the LP and $\mathrm{BMs}$ than in the $\mathrm{KO}$ group. Moreover, the nodules in the BM group decreased compared with in the LP group. This trend was consistent with ALP activity. Similar to the findings of previous studies, the present results confirmed that IGF-1R regulates osteoblast differentiation and mineralization. Furthermore, codon preference plays a role in regulating gene functions to a certain extent.

Like most receptors, IGF-1R is involved in or cross-talk with various signal pathways (Larsson et al., 2005; Tandon et al., 2016). Autophagy is a phenomenon that cannot be ignored during cell differentiation. It is regulated by multiple cellular pathways. Stimulation of autophagy is necessary for early osteoblast differentiation, which requires biphasic regulation of AMPK.
IGF-1R signaling stimulates AMPK activation, thereby resulting in autophagy activation at the early stage of differentiation (Xi et al., 2016). Alternatively, AKT activation stimulates AMPK S485 phosphorylation (Sarbassov et al., 2005), thus leading to the suppression of AMPK activation (reduction of T172 phosphorylation) and the termination of autophagy between days 9 and 15 (Xi et al., 2016). Therefore, we detected the related downstream signaling pathways of IGF-1R via Western blot. In contrast to the LP group, the BM group first upregulated the phosphorylation of AMPK and the expression of autophagosome components at the early stage of osteoblast differentiation. Thereafter, the LP group remained suppressed at the late stage of differentiation. These results suggested that the two haplotypes of IGF-1R may affect their differentiation patterns by changing the phosphorylation levels of downstream pathways during the period of AMPK induction. We further indicated that the haplotype of the $\mathrm{BM}$ group can promote early stage differentiation and delay the late stage differentiation. Furthermore, the haplotype of the BM group inhibits the expression of bone-related genes (Rux2, Alp, Ocn, Opn, and $O s x$ ) and decreases ALP activity and calcium deposition. Prior studies confirmed the positive selection of early maturation in the development of Bama Xiang pigs. Functional enrichment analysis indicated that autophagy regulation is one of the most important biological processes (Yang et al., 2018). From day 0 to day 160 , the growth curve of miniature pigs is approximately linear. By contrast, normal, fattening pigs have low average daily gain during the early growth stage, and it gradually increases 
after day 50 (Kohn et al., 2007). The results of previous studies were consistent with our findings that osteoblast differentiation in miniature pigs is more active during the early stage of growth and development than during the other growth stages. Therefore, we speculated that the polymorphisms of IGF-1R play a specific role in regulating the unique growth characteristics of miniature pigs. Further research is warranted to verify this hypothesis.

mRNA and protein stabilities can be affected by a synonymous codon change (Pedersen, 1984; Letzring et al., 2010). Chaney et al. demonstrated that the temporal coordination of co-translational folding is an additional mechanism of synonymous mutation in regulating translation dynamics (Chaney and Clark, 2015). Moreover, stable mRNA structures can lead to translational pauses ( $\mathrm{Tu}$ et al., 1992). Thus, the issue of whether the difference in functions between two haplotypes is due to stability changes remains uncertain. In this study, a significant difference was predicted between the mRNA secondary structures of the two different sequences of IGF-1R ECD. When the GTCT haplotype of the BM group changed to the CGTC haplotype of the LP group, the minimum free energy increased by $6.8 \mathrm{kcal}$. In addition, the mRNA stability of IGF-1R with the BM haplotype was higher than that of the LP haplotype, which was consisted with the prediction result of mRNA secondary structures and the minimum free energy for two haplotypes. A number of studies have shown that protein synthesis is affected by many factors, such as mRNA expression level, mRNA secondary structure, mRNA stability and so on (Mitsuo, 1999; Tsai et al., 2008; Hunt et al., 2014). Our results showed that the protein level of BM group was lower than that of LP group.

On the one hand, the mRNA expression level and mRNA stability of BM group were higher and the mRNA secondary structure was more stable than that of the LP group, which may affect the initiation of IGF-1R protein translation and protein synthesis. Meanwhile, there is a strong heterogeneity between different haplotypes caused by synonymous mutations. For example, in the synonymous mutations found by Cheng et al. (2018) the group with high mRNA stability and protein stability may have a low expression level. But Capon et al. (2004) described that synonymous mutations with high mRNA stability showed high protein expression. On the other hand, IGF-1R proteins in LP group have low stability, and the half-life is shorter than that in BM group. However, this possible effect is not enough to offset the higher IGF1R synthesis in LP group based on our detection results. In addition, the process of protein synthesis is also affected by other factors and these influence needs to be further studied.

On the basis of the four synonymous mutations of IGF1R ECD near the location of the IGF-1 binding domain, we speculated that the two haplotypes may have different binding affinities with IGF-1. The Co-IP experiment proved our conjecture that the relative binding rate of IGF-1 and IGF-1R significantly changed between the LP and BM groups. Moreover, the mechanisms underlying the relative difference in binding rates must be discussed. We considered that the number of receptors on the cell membrane surface changed.
Previous studies found that the mutations in the extracellular domain of receptors can change their expression on the cell membrane surface (Ip et al., 2018). This change may be the reason for the difference in the ligand-binding rates of the different haplotypes of Igfir. We detected a significant difference in the relative membranal expression rates of the two haplotypes IgfIr. We speculated further that the subtle changes in protein conformation of IGF-1R may affect transport, thereby decreasing the expression of receptors on the cell membrane. Numerous studies reported that genetic mutations can affect the changes in protein conformation. Atomic-level techniques, such as nuclear magnetic resonance or X-ray crystallography, can detect protein conformations. However, a study utilizing such techniques for detecting synonymous mutations has not been conducted yet. Subtle differences in protein conformations can also be inferred via differential immunodetection (Hunt et al., 2014). Proteins of different conformations have different binding efficiencies with a specific conformational sensitivity antibody. Thus, detecting conformation differences of proteins caused by synonymous mutations is a feasible method. In this study, conformation detection revealed that the synonymous mutation of IGF-1R changed the receptor's binding affinity with the IGF-1R antibody. We speculated that it might be the synonymous mutation that affected the conformation of IGF-1R protein. The difference in conformations of the two haplotypes of Igflr confirmed our prediction. We considered the difference as one of the reasons for the observed difference in binding capacity with IGF-1. These differences directly change the binding rates of IGF-1R and IGF-1. Moreover, these differences affect the transduction of intracellular signaling pathways and the differentiation of osteoblasts.

Owing to the extensive mechanisms of synonymous mutations and their random degrees of influence, several uncertainties and contingencies in the study of synonymous mutations remain. Therefore, the effects of synonymous mutations on the functions of specific genes must be explored. On the basis of the theory of codon preference, we observed that large pigs preferred to use common codons, whereas small pigs preferred rare codons. In combination with these results and the findings of previous studies, rare codons may lead to extreme translational pauses, provoke protein co-translation folding mechanisms, and change protein conformations and binding capacity (Tsai et al., 2008; Nissley et al., 2016). Synthesis of the receptor caused by synonymous mutations in the human dopamine receptor D2 (Drd2) alters mRNA stability (Duan et al., 2003). In turn, this alteration may affect the continuity of translation and even cause translational pause (Mitsuo, 1999). Synonymous mutations and ribosome stalling may lead to altered folding pathways. Although the conformational and functional differences between native and alternative states may be minor, subtle differences in conformations caused by synonymous mutations in $M d r 1$ ( $P$ glycoprotein) alter the structure of the substrate and inhibitor interaction sites (Tsai et al., 2008; Fung et al., 2014). Thus, even slight differences caused by synonymous mutations may affect physiological functions. In this study, we found that the difference in binding affinity with IGF-1 caused by the four Igfir synonymous mutations. Another study showed that a 
synonymous mutation of its ligand IGF-1 has similar effects (Cheng et al., 2018), suggesting that these findings are not isolated cases. Meanwhile, the codon preference differences between the large and miniature pigs we observed suggested that codon usage may be a factor regulating body size. Further studies are warranted to prove or falsify this hypothesis.

\section{CONCLUSION}

We detected two haplotypes formed by four synonymous mutations in IGF-1R ECD from pigs with different body size traits. These haplotypes may affect Igflr transcription and translation, IGF-1R protein conformation, and IGF-1 interactions, resulting in differences in osteoblast differentiation and mineralization. Furthermore, the linkage effects of these synonymous mutations may be involved in the formation of body size in miniature pigs. We explored the functions of potentially valuable synonymous mutations. Our results provide a theoretical basis for the formation of body size in miniature pigs.

\section{REFERENCES}

Adams, T. E., Epa, V. C., Garrett, T. P., and Ward, C. W. (2000). Structure and function of the type 1 insulin-like growth factor receptor. Cell Mol. Life. Sci. 57, 1050-1093. doi: 10.1007/PL00000744

Bae, S. J., Kim, H. J., Won, H. Y., Min, Y. K., and Hwang, E. S. (2017). Acceleration of osteoblast differentiation by a novel osteogenic compound, DMP-PYT, through activation of both the BMP and Wnt pathways. Sci. Rep. 7:8455. doi: 10.1038/s41598-017-08190-9

Baek, W. Y., Lee, M. A., Jung, J. W., Kim, S. Y., Akiyama, H., de Crombrugghe, B., et al. (2009). Positive regulation of adult bone formation by osteoblastspecific transcription factor osterix. J. Bone Miner. Res. 24, 1055-1065. doi: 10.1359/jbmr.081248

Baker, J., Liu, J. P., Robertson, E. J., and Efstratiadis, A. (1993). Role of insulinlike growth factors in embryonic and postnatal growth. Cell 75, 73-82. doi: 10.1016/s0092-8674(05)80085-6

Bancroft, G. N., Sikavitsas, V. I., van den Dolder, J., Sheffield, T. L., Ambrose, C. G., Jansen, J. A., et al. (2002). Fluid flow increases mineralized matrix deposition in $3 \mathrm{D}$ perfusion culture of marrow stromal osteoblasts in a dosedependent manner. Proc. Natl. Acad. Sci. U.S.A. 99, 12600-12605. doi: 10.1073/ pnas.202296599

Baxter, R. C. (2015). How IGF-1 activates its receptor. J. Cell. Commun. Signal. 9:87. doi: 10.1007/s12079-015-0276-8

Bin, X., Lin, C., Huang, X., Zhou, Q., Wang, L., and Xian, C. J. (2017). FGF-2 gene polymorphism in osteoporosis among Guangxi's Zhuang Chinese. Int. J. Mol. Sci. 18:E1358. doi: 10.3390/ijms18071358

Birnbaum, R. S., Bowsher, R. R., and Wiren, K. M. (1995). Changes in IGF-I and -II expression and secretion during the proliferation and differentiation of normal rat osteoblasts. J. Endocrinol. 144, 251-259. doi: 10.1677/joe.0.1440251

Canalis, E. (1993). Insulin like growth factors and the local regulation of bone formation. Bone 14, 273-276. doi: 10.1016/8756-3282(93)90151-y

Cao, C., Zhang, Y., Jia, Q., Wang, X., Zheng, Q., Zhang, H., et al. (2019). An exonic splicing enhancer mutation in DUOX2 causes aberrant alternative splicing and severe congenital hypothyroidism in Bama pigs. Dis. Model. Mech. 12:dmm036616. doi: 10.1242/dmm.036616

Capon, F., Allen, M. H., Ameen, M., Burden, A. D., Tillman, D., Barker, J. N., et al. (2004). A synonymous SNP of the corneodesmosin gene leads to increased mRNA stability and demonstrates association with psoriasis across diverse ethnic groups. Hum. Mol. Genet. 13, 2361-2368. doi: 10.1093/hmg/ddh273

Chai, X., Zhang, W., Chang, B., Feng, X., Song, J., Li, L., et al. (2019). GPR39 agonist TC-G 1008 promotes osteoblast differentiation and mineralization in

\section{DATA AVAILABILITY STATEMENT}

The original contributions presented in the study are included in the article/supplementary material, further inquiries can be directed to the corresponding author.

\section{AUTHOR CONTRIBUTIONS}

$\mathrm{LH}, \mathrm{CW}$, and SW conceived and designed the experiments. CW and SW performed the experiments. LH, CW, SW, SL, YC, HG, RY, TF, GL, XS, and JS assessed the experiments and provided the data analysis. CW and SW wrote the manuscript. All the authors read and approved the manuscript.

\section{FUNDING}

This work was supported by the National Natural Science Foundation of China (31772699 and 31672514) and the Natural Science Foundation of Jilin Province (20200201119JC).

MC3T3-E1 cells. Artif. Cells Nanomed. Biotechnol. 47, 3569-3576. doi: 10.1080/ 21691401.2019.1649270

Chaney, J. L., and Clark, P. L. (2015). Roles for synonymous codon usage in protein biogenesis. Annu. Rev. Biophys. 44, 143-166. doi: 10.1146/annurev-biophys060414-034333

Changhong, L., Mingguo, Z., Weiyi, H., Wenzhen, W., Rui, Y., and Linlin, H. (2018). Study on amplification of IGF1R gene and SNPs screening in different pig breeds. J. Jilin Agric. Univ. 40, 734-739. doi: 10.13327/j.jjlau.2018.4639

Cheng, Y., Chen, T., Song, J., Qi, Q., Wang, C., Xi, Q., et al. (2020). miR-709 inhibits GHRP6 induced GH synthesis by targeting PRKCA in pituitary. Mol. Cell. Endocrinol. 506:110763. doi: 10.1016/j.mce.2020.110763

Cheng, Y., Liu, S., Wang, G., Wei, W., Huang, S., Yang, R., et al. (2018). Porcine IGF1 synonymous mutation alter gene expression and protein binding affinity with IGF1R. Int. J. Biol. Macromol. 116, 23-30. doi: 10.1016/j.ijbiomac.2018. 05.022

Cheng, Y., Liu, S., Zhang, X., Wu, Q., Li, S., Fu, H., et al. (2016). Expression profiles of IGF-1R gene and polymorphisms of its regulatory regions in different pig breeds. Protein J. 35, 231-236. doi: 10.1007/s10930-016-9666-x

Curran, J. F., and Yarus, M. (1989). Rates of aminoacyl-tRNA selection at 29 sense codons in vivo. J. Mol. Biol. 209, 65-77. doi: 10.1016/0022-2836(89)90170-8

Ding, S., Wu, X., Li, G., Han, M., Zhuang, Y., and Xu, T. (2005). Efficient transposition of the piggyBac (PB) transposon in mammalian cells and mice. Cell 122, 473-483. doi: 10.1016/j.cell.2005.07.013

Duan, J., Wainwright, M. S., Comeron, J. M., Naruya, S., Sanders, A. R., Joel, G., et al. (2003). Synonymous mutations in the human dopamine receptor D2 (DRD2) affect mRNA stability and synthesis of the receptor. Hum. Mol. Genet. 12, 205-216. doi: 10.1093/hmg/ddg055

Ducy, P., Rui, Z., Geoffroy, V., Ridall, A. L., and Karsenty, G. (1997). Osf2/Cbfa1: a transcriptional activator of osteoblast differentiation. Cell 89, 747-754. doi: 10.1016/s0092-8674(00)80257-3

Efstratiadis, A. (1998). Genetics of mouse growth. Int. J. Dev. Biol. 42, 955-976.

Fang, Y., Xue, Z., Zhao, L., Yang, X., Yang, Y., Zhou, X., et al. (2019). Calycosin stimulates the osteogenic differentiation of rat calvarial osteoblasts by activating the IGF1R/PI3K/Akt signaling pathway. Cell Biol. Int. 43, 323-332. doi: 10. 1002/cbin. 11102

Fung, K. L., Pan, J., Ohnuma, S., Lund, P. E., Pixley, J. N., Kimchi-Sarfaty, C., et al. (2014). MDR1 synonymous polymorphisms alter transporter specificity and protein stability in a stable epithelial monolayer. Cancer Res. 74, 598-608. doi: 10.1158/0008-5472.CAN-13-2064

Gaffney-Stomberg, E., Lutz, L. J., Shcherbina, A., Ricke, D. O., Petrovick, M., Cropper, T. L., et al. (2017). Association between single gene polymorphisms 
and bone biomarkers and response to calcium and vitamin D supplementation in young adults undergoing military training. J. Bone. Miner. Res. 32, 498-507. doi: $10.1002 /$ jbmr.3008

Golub, E. E., Harrison, G., Taylor, A. G., Camper, S., and Shapiro, I. M. (1992). The role of alkaline phosphatase in cartilage mineralization. Bone Miner. 17, 273-278. doi: 10.1016/0169-6009(92)90750-8

Grabundzija, I., Irgang, M., Mátés, L., Belay, E., Matrai, J., Gogol-DRing, A., et al. (2010). Comparative analysis of transposable element vector systems in human cells. Mol. Ther. J. Am. Soc. Gene Ther. 18, 1200-1209. doi: 10.1038/mt. 2010.47

Harmel, E. M., Binder, G., Barnikol-Oettler, A., Caliebe, J., Kiess, W., Losekoot, M., et al. (2013). Alu-mediated recombination defect in IGF1R: haploinsufficiency in a patient with short stature. Horm. Res. Paediatr. 80, 431-442. doi: 10.1159/ 000355410

Horvath, P., Balla, B., Kosa, J. P., Tobias, B., Szili, B., Kirschner, G., et al. (2016). Strong effect of SNP rs4988300 of the LRP5 gene on bone phenotype of Caucasian postmenopausal women. J. Bone Miner. Metab. 34, 79-85. doi: 10. 1007/s00774-014-0645-z

Hosseini, S., Naderi-Manesh, H., Vali, H., Baghaban Eslaminejad, M., Azam Sayahpour, F., Sheibani, S., et al. (2019). Contribution of osteocalcin-mimetic peptide enhances osteogenic activity and extracellular matrix mineralization of human osteoblast-like cells. Coll. Surf. B Biointerfaces 173, 662-671. doi: 10.1016/j.colsurfb.2018.10.035

Hunt, R. C., Simhadri, V. L., Iandoli, M., Sauna, Z. E., and Kimchi-Sarfaty, C. (2014). Exposing synonymous mutations. Trends Genet. 30, 308-321. doi: 10. 1016/j.tig.2014.04.006

Ip, C. K. M., Ng, P. K. S., Jeong, K. J., Shao, S. H., Ju, Z., Leonard, P. G., et al. (2018). Neomorphic PDGFRA extracellular domain driver mutations are resistant to PDGFRA targeted therapies. Nat. Commun. 9:4583. doi: 10.1038/s41467-01806949-w

Jansson, M., Hallen, D., Koho, H., Andersson, G., Berghard, L., Heidrich, J., et al. (1997). Characterization of ligand binding of a soluble human insulinlike growth factor I receptor variant suggests a ligand-induced conformational change. J. Biol. Chem. 272, 8189-8197. doi: 10.1074/jbc.272.13.8189

Jiang, H. T., Ran, C. C., Liao, Y. P., Zhu, J. H., Wang, H., Deng, R., et al. (2019). IGF-1 reverses the osteogenic inhibitory effect of dexamethasone on BMP9-induced osteogenic differentiation in mouse embryonic fi broblasts via PI3K/AKT/COX-2 pathway. J. Steroid Biochem. Mol. Biol. 191:105363. doi: 10.1016/j.jsbmb.2019.04.012

Joshi, M. U., Pittman, H. K., Haisch, C. E., and Verbanac, K. M. (2008). Real-time PCR to determine transgene copy number and to quantitate the biolocalization of adoptively transferred cells from EGFP-transgenic mice. Biotechniques 45, 247-258. doi: 10.2144/000112913

Joung, Y. H., Lim, E. J., Darvin, P., Jang, J. W., Park, K. D., Lee, H. K., et al. (2013). Hwanggeumchal sorghum extract enhances BMP7 and GH signaling through the activation of Jak2/STAT5B in MC3T3E1 osteoblastic cells. Mol. Med. Rep. 8, 891-896. doi: 10.3892/mmr.2013.1593

Kohn, F., Sharifi, A. R., and Simianer, H. (2007). Modeling the growth of the Goettingen minipig. J. Anim. Sci. 85, 84-92. doi: 10.2527/jas.2006-271

Larsson, O., Girnita, A., and Girnita, L. (2005). Role of insulin-like growth factor 1 receptor signalling in cancer. Br. J. Cancer 92, 2097-2101. doi: 10.1038/sj.bjc. 6602627

LeRoith, D., Werner, H., Beitner-Johnson, D., and Roberts, C. T. Jr. (1995). Molecular and cellular aspects of the insulin-like growth factor I receptor. Endocr. Rev. 16, 143-163. doi: 10.1210/edrv-16-2-143

Letzring, D. P., Dean, K. M., and Grayhack, E. J. (2010). Control of translation efficiency in yeast by codon-anticodon interactions. RNA 16, 2516-2528. doi: $10.1261 /$ rna. 2411710

Liu, H. B., Lv, P. R., He, R. G., Yang, X. G., Qin, X. E., Pan, T. B., et al. (2010). Cloned Guangxi Bama minipig (Sus scrofa) and its offspring have normal reproductive performance. Cell Reprogram 12, 543-550. doi: 10.1089/cell.2009.0094

Liu, T. C., Hsieh, M. J., Liu, M. C., Chiang, W. L., Tsao, T. C., and Yang, S. F. (2016). The clinical significance of the insulin-like growth factor-1 receptor polymorphism in non-small-cell lung cancer with epidermal growth factor receptor mutation. Int. J. Mol. Sci. 17:763. doi: 10.3390/ijms17050763

Mitsuo, Z. (1999). Correlation between mRNA structure of the coding region and translational pauses. Nucleic Acids Symp. 42, 81-82. doi: 10.1093/nass/42.1.81

Nieves, J. W., Formica, C., Ruffing, J., Zion, M., Garrett, P., Lindsay, R., et al. (2005). Males have larger skeletal size and bone mass than females, despite comparable body size. J. Bone Miner. Res. 20, 529-535. doi: 10.1359/JBMR. 041005

Nissley, D. A., Sharma, A. K., Ahmed, N., Friedrich, U. A., Kramer, G., Bukau, B., et al. (2016). Accurate prediction of cellular co-translational folding indicates proteins can switch from post- to co-translational folding. Nat. Commun. 7:10341. doi: 10.1038/ncomms10341

Orimo, H., and Shimada, T. (2008). The role of tissue-nonspecific alkaline phosphatase in the phosphate-induced activation of alkaline phosphatase and mineralization in SaOS-2 human osteoblast-like cells. Mol. Cell. Biochem. 315, 51-60. doi: 10.1007/s11010-008-9788-3

Pantovic, A., Krstic, A., Janjetovic, K., Kocic, J., Harhaji-Trajkovic, L., Bugarski, D., et al. (2013). Coordinated time-dependent modulation of AMPK/Akt/mTOR signaling and autophagy controls osteogenic differentiation of human mesenchymal stem cells. Bone 52, 524-531. doi: 10.1016/j.bone.2012.10.024

Pedersen, S. (1984). Escherichia coli ribosomes translate in vivo with variable rate. EMBO J. 3, 2895-2898. doi: 10.1002/j.1460-2075.1984.tb02227.x

Plotkin, J. B., and Kudla, G. (2011). Synonymous but not the same: the causes and consequences of codon bias. Nat. Rev. Genet. 12, 32-42. doi: 10.1038/nrg2899

Prather, R. S., Lorson, M., Ross, J. W., Whyte, J. J., and Walters, E. (2013). Genetically engineered pig models for human diseases. Annu. Rev. Anim. Biosci. 1, 203-219. doi: 10.1146/annurev-animal-031412-103715

Puchtler, H., Meloan, S. N., and Terry, M. S. (1969). On the history and mechanism of alizarin and alizarin red S stains for calcium. J. Histochem. Cytochem. 17, 110-124. doi: 10.1177/17.2.110

Rezgui, D., Williams, C., Savage, S. A., Prince, S. N., Zaccheo, O. J., Jones, E. Y., et al. (2009). Structure and function of the human Gly1619Arg polymorphism of M6P/IGF2R domain 11 implicated in IGF2 dependent growth. J. Mol. Endocrinol. 42, 341-356. doi: 10.1677/JME-08-0154

Ruff, C. (2003). Growth in bone strength, body size, and muscle size in a juvenile longitudinal sample. Bone 33, 317-329. doi: 10.1016/s8756-3282(03)00161-3

Sarbassov, D. D., Guertin, D. A., Ali, S. M., and Sabatini, D. M. (2005). Phosphorylation and regulation of Akt/PKB by the rictor-mTOR complex. Science 307, 1098-1101. doi: 10.1126/science.1106148

Sauna, Z. E., Okunji, C., Hunt, R. C., Gupta, T., Allen, C. E., Plum, E., et al. (2009). Characterization of conformation-sensitive antibodies to ADAMTS13, the von Willebrand cleavage protease. PLoS One 4:e6506. doi: 10.1371/journal.pone. 0006506

Schlecht, S. H., Bigelow, E. M., and Jepsen, K. J. (2015). How does bone strength compare across sex, site, and ethnicity? Clin. Orthop. Relat. Res. 473, 2540-2547. doi: 10.1007/s11999-015-4229-6

Siddle, K. (2011). Signalling by insulin and IGF receptors: supporting acts and new players. J. Mol. Endocrinol. 47, R1-R10. doi: 10.1530/JME-11-0022

Smit, M. H. D., and Duin, J. V. (1990). Secondary structure of the ribosome binding site determines translational efficiency: a quantitative analysis. Proc. Natl. Acad. Sci. U.S.A. 87, 7668-7672. doi: 10.1073/pnas.87.19.7668

Srensen, M., and Pedersen, S. (1991). Absolute in vivo translation rates of individual codons in Escherichia coli. The two glutamic acid codons GAA and GAG are translated with a threefold difference in rate. J. Mol. Biol. 222, 265-280. doi: 10.1016/0022-2836(91)90211-n

Szewczuk, M., Zych, S., Wojcik, J., and Czerniawska-Piatkowska, E. (2013). Association of two SNPs in the coding region of the insulin-like growth factor 1 receptor (IGF1R) gene with growth-related traits in Angus cattle. J. Appl. Genet. 54, 305-308. doi: 10.1007/s13353-013-0155-z

Tandon, M., Chen, Z., Othman, A. H., and Pratap, J. (2016). Role of Runx2 in IGF-1Rbeta/Akt- and AMPK/Erk-dependent growth, survival and sensitivity towards metformin in breast cancer bone metastasis. Oncogene 35, 4730-4740. doi: 10.1038/onc.2015.518

Tsai, C. J., Sauna, Z. E., Kimchi-Sarfaty, C., Ambudkar, S. V., Gottesman, M. M., and Nussinov, R. (2008). Synonymous mutations and ribosome stalling can lead to altered folding pathways and distinct minima. J. Mol. Biol. 383, 281-291. doi: 10.1016/j.jmb.2008.08.012

Tu, C., Tzeng, T. H., and Bruenn, J. A. (1992). Ribosomal movement impeded at a pseudoknot required for frameshifting. Proc. Natl. Acad. Sci. U.S.A. 89, 8636-8640. doi: 10.1073/pnas.89.18.8636

Wallborn, T., Wuller, S., Klammt, J., Kruis, T., Kratzsch, J., Schmidt, G., et al. (2010). A heterozygous mutation of the insulin-like growth factor-I receptor causes retention of the nascent protein in the endoplasmic reticulum and results in intrauterine and postnatal growth retardation. J. Clin. Endocrinol. Metab. 95, 2316-2324. doi: 10.1210/jc.2009-2404 
Wang, C., Liu, S., Wu, Q., Cheng, Y., Feng, T., Song, J., et al. (2020). Porcine IGF1R synonymous mutations in the intracellular domain affect cell proliferation and alter kinase activity. Int. J. Biol. Macromol. 152, 147-153. doi: 10.1016/j. ijbiomac.2020.02.281

Wang, T., Wang, Y., Menendez, A., Fong, C., Babey, M., Tahimic, C. G., et al. (2015). Osteoblast-specific loss of IGF1R signaling results in impaired endochondral bone formation during fracture healing. J. Bone. Miner. Res. 30, 1572-1584. doi: 10.1002/jbmr.2510

Wang, X., Wei, R., Li, Q., Liu, H., Huang, B., Gao, J., et al. (2013). PK-15cells transfected with porcine CD163 by PiggyBac transposon system are susceptible to porcine reproductive and respiratory syndrome virus. J. Virol. Methods 193, 383-390. doi: 10.1016/j.jviromet.2013.06.035

Wei, W., Liu, S., Song, J., Feng, T., Yang, R., Cheng, Y., et al. (2020). MGF-19E peptide promoted proliferation, differentiation and mineralization of MC3T3E1 cell and promoted bone defect healing. Gene 749:144703. doi: 10.1016/j.gene. 2020.144703

Whitten, A. E., Smith, B. J., Menting, J. G., Mai, B. M., Mckern, N. M., Lovrecz, G. O., et al. (2009). Solution structure of ectodomains of the insulin receptor family: the ectodomain of the type 1 insulin-like growth factor receptor displays asymmetry of ligand binding accompanied by limited conformational change. J. Mol. Biol. 394, 878-892. doi: 10.1016/j.jmb.2009.10.011

Whyte, M. P. (1994). Hypophosphatasia and the role of alkaline phosphatase in skeletal mineralization. Endocr. Rev. 15, 439-461. doi: 10.1210/edrv-15-4-439

Xi, G., Rosen, C. J., and Clemmons, D. R. (2016). IGF-I and IGFBP-2 stimulate AMPK activation and autophagy, which are required for osteoblast differentiation. Endocrinology 157, 268-281. doi: 10.1210/en.2015-1690
Yang, Y., Adeola, A. C., Xie, H. B., and Zhang, Y. P. (2018). Genomic and transcriptomic analyses reveal selection of genes for puberty in Bama Xiang pigs. Zool. Res. 39, 424-430. doi: 10.24272/j.issn.2095-8137.2018.068

Zafra, M. P., Schatoff, E. M., Katti, A., Foronda, M., Breinig, M., Schweitzer, A. Y., et al. (2018). Optimized base editors enable efficient editing in cells, organoids and mice. Nat. Biotechnol. 36, 888-893. doi: 10.1038/nbt.4194

Zhao, G., Monier-Faugere, M. C., Langub, M. C., Geng, Z., Nakayama, T., Pike, J. W., et al. (2000). Targeted overexpression of insulin-like growth factor I to osteoblasts of transgenic mice: increased trabecular bone volume without increased osteoblast proliferation. Endocrinology 141, 2674-2682. doi: 10.1210/ endo.141.7.7585

Zheng, X., Dai, J., Zhang, H., and Ge, Z. (2018). MicroRNA-221 promotes cell proliferation, migration, and differentiation by regulation of ZFPM2 in osteoblasts. Braz. J. Med. Biol. Res. 51:e7574. doi: 10.1590/1414-431X20187574

Conflict of Interest: The authors declare that the research was conducted in the absence of any commercial or financial relationships that could be construed as a potential conflict of interest.

Copyright (c) 2020 Wang, Wang, Liu, Cheng, Geng, Yang, Feng, Lu, Sun, Song and Hao. This is an open-access article distributed under the terms of the Creative Commons Attribution License (CC BY). The use, distribution or reproduction in other forums is permitted, provided the original author(s) and the copyright owner(s) are credited and that the original publication in this journal is cited, in accordance with accepted academic practice. No use, distribution or reproduction is permitted which does not comply with these terms. 